NBER WORKING PAPER SERIES

THE POLITICAL ECONOMY OF SOCIAL SECURITY REFORM

Michael J. Boskin

Diego J. Perez

Daniel S. Bennett

Working Paper 25985

http://www.nber.org/papers/w25985

\author{
NATIONAL BUREAU OF ECONOMIC RESEARCH \\ 1050 Massachusetts Avenue \\ Cambridge, MA 02138 \\ June 2019
}

We thank Pablo Villanueva, John Cherian, Daniel Wright, Daniel Begovich and Neal Begovich for their excellent work as research assistants, participants in the Hoover Institution Economic Policy Working Group Seminar for helpful suggestions, Dave Brady and Doug Rivers for assistance with the Hoover Institution Survey on Social Security, and Daron Acemoglu, Mordecai Kurz, and Roger Myerson for helpful game theory insights. The views expressed herein are those of the authors and do not necessarily reflect the views of the National Bureau of Economic Research.

NBER working papers are circulated for discussion and comment purposes. They have not been peer-reviewed or been subject to the review by the NBER Board of Directors that accompanies official NBER publications.

(C) 2019 by Michael J. Boskin, Diego J. Perez, and Daniel S. Bennett. All rights reserved. Short sections of text, not to exceed two paragraphs, may be quoted without explicit permission provided that full credit, including $(\odot)$ notice, is given to the source. 
The Political Economy of Social Security Reform

Michael J. Boskin, Diego J. Perez, and Daniel S. Bennett

NBER Working Paper No. 25985

June 2019

JEL No. H55,H62,H68

\section{ABSTRACT}

We identify which types of Social Security reforms are supported when people vote in their financial self-interest, under alternative economic and demographic projections and voting proclivity assumptions. While $40 \%$ of voters have negative lifetime net transfers, less than $10 \%$ have negative future transfers under the un- sustainable status quo. Framing the problem as a choice between reforms is necessary for any to receive majority support. Delayed reforms are often preferred, but immediate tax hikes or slower benefit growth win in some circumstances. Inter-generational AND intragenerational heterogeneity of economic interests combine to affect which reforms are blocked and which are feasible.

Michael J. Boskin

Hoover Institution

Stanford University

434 Galvez Mall

Stanford, CA 94305-6010

and NBER

boskin@stanford.edu

Diego J. Perez

Department of Economics

New York University

19 West 4th Street, 6th Floor

New York, NY 10012

USA

diego.perez@nyu.edu
Daniel S. Bennett

Stanford University

dsbennet@ stanford.edu

A data appendix is available at http://www.nber.org/data-appendix/w25985 


\title{
The Political Economy of Social Security Reform
}

\author{
By Michael J. Boskin, Diego J. Perez, and Daniel S. Bennett*
}

\begin{abstract}
We identify which types of Social Security reforms are supported when people vote in their financial self-interest, under alternative economic and demographic projections and voting proclivity assumptions. While $40 \%$ of voters have negative lifetime net transfers, less than 10\% have negative future transfers under the unsustainable status quo. Framing the problem as a choice between reforms is necessary for any to receive majority support. Delayed reforms are often preferred, but immediate tax hikes or slower benefit growth win in some circumstances. Intergenerational AND intragenerational heterogeneity of economic interests combine to affect which reforms are blocked and which are feasible.
\end{abstract}

On August 14th 1935, President Roosevelt signed the Social Security Act, describing it as, “... a law that will give some measure of protection to the average citizen and to his family against ... poverty-ridden old age..." Since its inception, the program has helped to achieve that goal. People 65 and older are more than two thirds less likely to live below the poverty line than they were 50 years ago, and are less likely to live in poverty than those $18-64 .^{2}$ Indeed, Social Security's contribution to the reduction of poverty is twice as large, and for the elderly in particular, twenty times as large, as the contribution of all means-tested transfer programs combined (Meyer and $\mathrm{Wu}(2018)$ ). It is by far the largest transfer program in American history and has consistently enjoyed overwhelming public support. ${ }^{3}$ In 2018, over 176 million people had earnings subject to Social Security payroll taxes; sixty three million received benefits.

Despite its popularity, Social Security is at risk of a serious crisis in coming years. Rising real benefits, the retirement of baby-boomers, and increasing lifespans for beneficiaries, among other factors, have strained its financial sustainability. Since 2009, yearly benefits paid have exceeded tax revenues. The Trustees estimate that the SSA Trust Fund will be exhausted by 2035, at which time the program will only be able to pay $77 \%$ of benefits. The size of the unfunded liabilities of Social Security rivals that of the publicly held national debt.

The Congressional Budget Office (Congressional Budget Office (2018)) and Technical Panel on the SSA's methods (et. al. (2015)) both find the SSA's estimate of the actuarial deficit far too small. Similarly, CBO and the technical panel conclude that the combined trust fund will be exhausted by 2031 and 2033 respectively, and according to the CBO's estimates, taxes in 2031 will be sufficient to pay only $71 \%$ of benefits.

\footnotetext{
* Boskin: Stanford University, Landau Economics Building 579 Serra Mall Stanford, CA, 94305, boskin@stanford.edu. Perez: New York University, Economics Department 19 W 4th Street 6FL New York, NY 10012, diego.perez@nyu.edu. Bennett: Stanford University, Landau Economics Building 579 Serra Mall Stanford, CA, 94305 dsbennet@stanford.edu. We thank Pablo Villanueva, John Cherian, Daniel Wright, Daniel Begovich, and Neal Begovich for their excellent work as research assistants, participants in the Hoover Institution Economic Policy Working Group Seminar for helpful suggestions, Dave Brady and Doug Rivers for assistance with the Hoover Institution Survey on Social Security, and Daron Acemoglu, Mordecai Kurz, and Roger Myerson for helpful game theory insights.

${ }^{1}$ Presidential Statement, August 14th, 1935.

${ }^{2}$ Census Bureau, Income and Poverty in the United States: 2017

${ }^{3}$ For example, in a CBS News Poll, January 2014, $73 \%$ of adults said the benefits of Social Security are worth the costs.
} 
The popularity of Social Security coupled with its obvious impending financial problems raise the natural question: "Why is reform not a higher priority for policy makers?" The last major reform to Social Security occurred over a third of a century ago, in 1983, and while it contained laudable features, such as gradually raising the retirement age in the distant future, it quickly became apparent that the reforms were not sufficient to provide permanent solvency (Boskin (1986)). In the years preceding the 1983 reform, Social Security's financial problems were more immediate; the 1981 Trustees' Report estimated that the fund would be exhausted in the latter half of 1982 . But the 75 year actuarial deficit in the 1981 report was $.93 \%$ of taxable payroll, less than one third of today's estimate. Since 1983, the worker to beneficiary ratio has decreased from 3.2 to 2.8 , and it is expected to decline to 2.3 workers per beneficiary by 2030 . Life expectancy at age 65 has increased by more than three years (for Health Statistics (2017)), and average real benefits are at least $40 \%$ higher.

In 2012, President Obama's budget proposed using a chained-CPI to make cost of living adjustments in entitlement programs, which would have slowed real benefit growth; but by 2014, a chained-CPI had been removed from his proposed budgets. ${ }^{4}$ In the 2016 presidential election, neither major party candidate included solving Social Security's financial problems in their platform. Donald Trump stated that, "It is absolutely my intention to leave Social Security the way it is." Hillary Clinton specifically suggested eliminating the cap on earnings subject to the payroll tax, which would have significantly increased revenues, but also proposed simultaneously raising benefits (Horsley (2016)).

The Social Security 2100 Act (2019) was one of the first bills introduced in the new Congress with over 200 cosponsors (all Democrats). The bill would slightly more than eliminate the actuarial deficit of Social Security by raising the payroll tax rate almost $20 \%$ to $14.8 \%$, and by phasing out the maximum on taxable earnings. It would also raise benefits, especially for low income recipients, by changing the formula for calculating benefits, imposing a larger minimum benefit, and making cost of living adjustments more generous. The Republican controlled Senate is universally expected to reject the proposal.

The goal of this paper is to contribute to a better understanding of the political economy of Social Security reform proposals. We suggest a possible reason why reform has remained so elusive, when the program is so popular and the threat is rapidly approaching. The fact that individuals pay taxes earlier in their life cycle than they receive benefits and the heterogeneity of transfers across and within generations are key drivers of the results. Waiting to reform the program is very attractive to many voters, including middle age and relatively young voters, because even though their lifetime "deal" from Social Security may be negative, the taxes they have left to pay going forward will be less than the benefits they expect to receive. Based thereon, we estimate the likely support various archetypical reforms would receive, and demonstrate how alternative voting behaviors, intergenerational concerns, and perceived alternative options affect the outcomes. We also explore potential coalition formation, to promote or obstruct proposed reforms.

We run a series of hypothetical pairwise Social Security reform referenda under alternative assumed voting patterns and economic and demographic projections. We explore which reforms

\footnotetext{
${ }^{4}$ By law, cost of living adjustments to benefits are indexed to the CPI-W, which is calculated using urban wage earners expenditure patterns. A chained CPI, which approximately eliminates substitution bias, would have replaced the CPI-W.
} 
are most likely to be supported, by whom, under what conditions. Delayed reforms usually beat immediate reforms; which delayed reforms win depends on which set of macroeconomic and demographic assumptions, SSA or CBO, is used. Exclusion of those near retirement from benefit changes is sufficient for immediate reforms to win under some scenarios. Increasing the representation of young voters enhances the likelihood of immediate reform prevailing, e.g. raising young voter relative turnout from American to European levels could also be sufficient. Alternative representations of the interests of those currently too young to vote, e.g. parents concern for their children or institution of a voting trust representing their interests are powerful forces for immediate reform. Among immediate reforms, switching from wage to price indexing plus modest partial means testing for higher income beneficiaries appears to be the only reform capable of withstanding a blocking coalition.

Our paper is organized as follows. Section I provides a brief review of some political economy literature, background information describing the main features of our calculations, our methodology, and the data used in constructing hypothetical referendums. Section II describes estimates of, and patterns in, expected total and remaining lifetime benefits, taxes, and transfers for population archetypes of differing age, lifetime earnings, and marital status. Section III describes the archetypical reforms, voting proclivities, and the economic and demographic assumptions underlying alternative sets of results. Section IV presents the main results on referenda, showing that the framing of choices for pairwise referendums strongly affects outcomes. We then explore how changes in voting behavior can influence results. Section V discusses the sensitivity of our results to the alternative sets of economic and demographic assumptions. Section VI provides a preliminary look at the formation of coalitions both to pass and to block reform, by examining whose votes might most easily be switched and the aggregate value at stake. Section VII presents a brief conclusion. Extensive sensitivity analysis to various assumptions and a more detailed description of methods and data are contained in the Appendix.

\section{Background Information, Methodology, and Data}

\section{A. Review of Political Economy Literature}

It is worthwhile generalizing the simple current political economy question of why reform is so difficult to a brief discussion of the political economy theory of intergenerational redistribution, such as from a pay as you go financed Social Security system. In a majority rule, direct democracy political equilibrium, the preferences of the median voter will tend to decide outcomes. ${ }^{5,6}$ Population growth and a generally longer working than retired life implies that younger taxpaying voters outnumber older benefit receiving voters. Currently there are about three covered workers per beneficiary. Since the younger generation pays taxes to fund the older generations benefits, why dont they just vote to stop paying the taxes? And how did a pay as you go system that enables the generation of retired recipients to gain at its start up, and at every expansion,

\footnotetext{
${ }^{5}$ Hotelling, also Black; and as applied by many others.

${ }^{6}$ The conditions for the median voter theorem's result to apply are fairly strong, e.g. decisions are made by committees with open competitive agendas, two candidates single issue election platforms, or referenda with voters revealing preferences with the chosen result the median. Traditional concerns include the need for single-peakedness, intransitivity, and strategic voting. But median voter models remain the workhorse, or at least the baseline, in political economy models.
} 
at the expense of younger current and future tax payers get enacted and expanded? How do such programs remain politically viable, even popular, over time?

Clearly, someone eventually has to pay for the unfunded liabilities and make up for historical and future transfers to the old. As Samuelson (1958) showed in his original overlapping generations model, a pay as you go unfunded Social Security system can be sustainable with constant population and wage growth with a rate of return equal to the growth rate. The required tax rate is equal to the product of the replacement rate and dependency ratio. ${ }^{7}$ As Feldstein (1977), Aaron (1966), and others have noted, the implicit rate of return in such a system, approximately the sum of the rate of population and real wage growth, is generally less than the marginal product of tangible capital and therefore there are potential gains from prefunding as opposed to pay as you go financing.

A variety of insights have been offered to help explain why a majority would adopt a pay as you go system larger than younger generations would prefer. Browning (1971), Hammond (n.d.) , and Sjoblom (1985) developed important early models, with homogeneous populations differing only by age, and did not examine the possibility of future voters changing or abolishing the system in their favor. Importantly, Tabellini (1990) showed that heterogeneity within generations enables a majority coalition to form across generations capable of sustaining the redistribution program. That insight, receives strong support in our results. Alternatively, Boadway and Wildasin (1989) show how borrowing constraints in a model with a capital market can yield a voting equilibrium with non-zero levels of Social Security, although numerous issues, such as the need to impose extremely infrequent voting, limit generality.

These models consider the interests, generally defined as the net gain or loss from Social Security (or, analogously public debt) of voters of different circumstances in the determination of the political economy equilibrium. They determine the level and structure of taxes and benefits across different population characteristics and its political sustainability, with and without some pre-commitment mechanism. Issues of population heterogeneity, other than earning ability, are ignored. While that simplifies the analysis, it prevents the possibility of specially targeted transfers to build, or conversely, to block a winning coalition. The classic insight in this spirit is called Directors Law (Stigler (1970)): redistribution will favor the middle class at the expense of the rich and the poor. Meltzer and Richard (1981) address the more general problem of the political economy determination of an overall tax rate and universal income transfers. Dixit and Londregan (1996) analyze incentives in a more general model detailing which particular groups political parties or coalitions will target: those easiest, i.e. not very costly, to secure, even while potentially decreasing the surplus of other members of the winning coalition. In this spirit, we present examples of potential coalition formation over Social Security reform in Section VI.

A number of other studies have used groups of individual worker-beneficiaries similar to our archetypes to evaluate the distributional impacts of Social Security. These include Boskin et al. (1987), Boskin and Shoven (1987), Goda, Shoven and Slavov (2015), and Steuerle and Quakenbush (2015), not to mention many studies by the SSA. We take this type of analysis further, by using observed voting patterns to infer how these distributional impacts affect the political process that determines the benefits and taxes of the program. We use an intuitive application of game theoretic concepts to understand why reform has been so difficult. Our analysis enables

${ }^{7}$ The ratio of benefits to wages, and retirees to workers, respectively. 
us to examine the viability of alternative, proposed reforms to benefits and taxes, beginning now or in the future, and provide insights into which population subgroups support or oppose these potential reforms. This also allows us to examine how voter inertia, intergenerational concerns, and coalition formation among voters may impact political economy outcomes. Our results lend strong support to Tabellini (1990), that intergenerational and intragenerational heterogeneity of interests align enabling coalitions sustaining Social Security to form.

To help identify what attitudes, opinions, and information might be contributing to the lack of reform, we utilized the 2017 Hoover Institution Survey on Social Security. The survey, performed through YouGov, asks detailed questions of a sample, balanced by age and other factors, to explore what respondents understand about Social Security and their policy preferences. Table 1 shows responses to selected survey questions. One possible explanation for the delay could be that voters are unaware of the problem, or do not believe it is serious. However, $67 \%$ of survey respondents agreed that Social Security is headed for a financial crisis in the future, and, amazingly, only $18 \%$ of respondents believed that Social Security will definitely exist when they retire. It thus seems unlikely that the delay in reform is caused by a lack of awareness.

Table 1-: Hoover Institution 2017 Survey on Social Security: Selected Question Responses

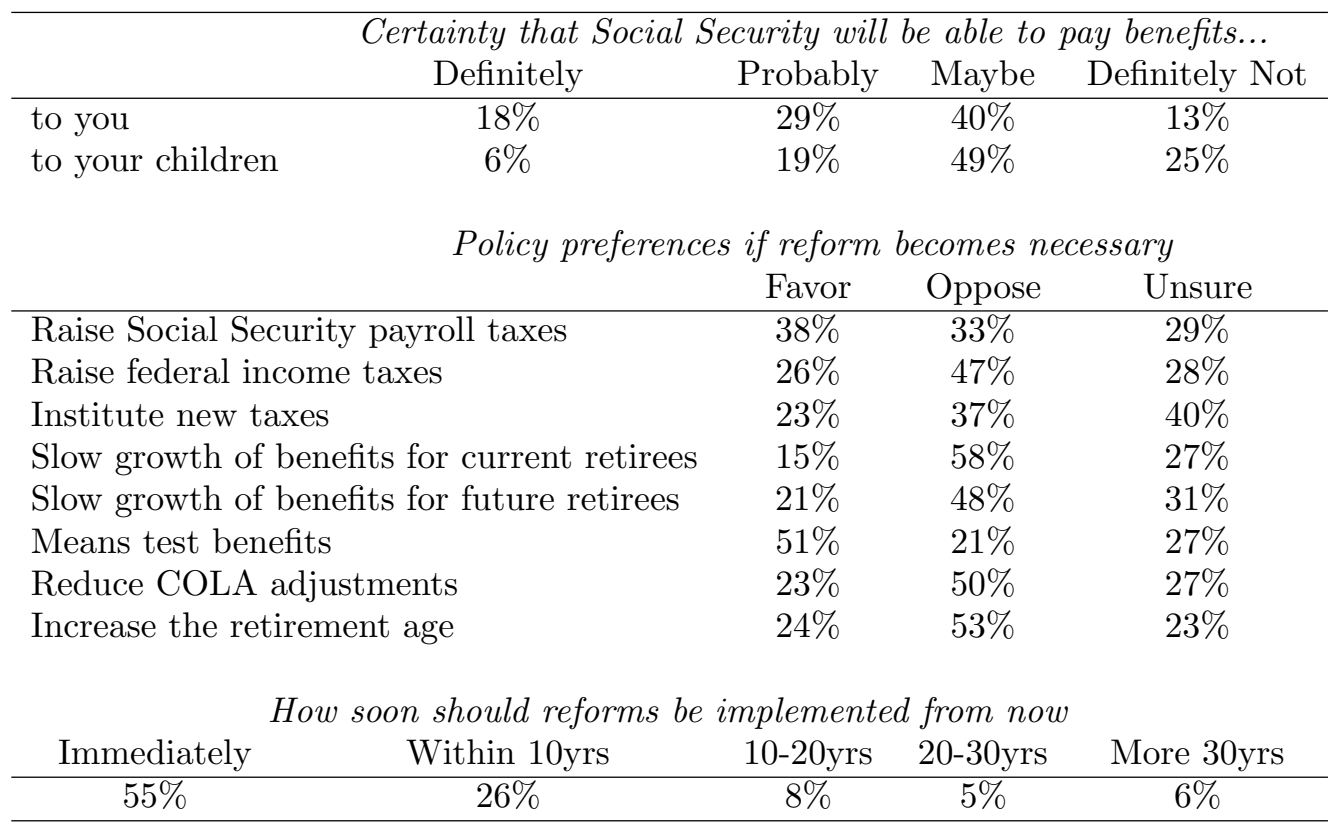

note: Descriptions in the table are not the exact wording of questions and are shortened for the sake of brevity.

It is also not caused by a preference among voters for delaying reform. Fifty-five percent of respondents said reform should happen now, while an additional $26 \%$ said reform should happen within the next ten years. Most voters seem to understand that there are benefits to acting now, 
as opposed to waiting until the trust fund is exhausted. These include: phasing in reforms over a longer period of time, giving people time to adjust their labor force participation, retirement, and saving behavior; reducing the risk of macroeconomic disruptions due to sudden large changes in taxes and benefits; spreading the burden of reform more equally across generations; and improving welfare by eliminating uncertainty costs around when and how the program will change. $^{8}$

\section{B. Methodology and Data}

The paper concentrates on the largest categories of benefits, namely retirement and disability insurance. Social Security's main source of revenue is a payroll tax, levied on employers and employees of $6.2 \%$ of wages. Wages are taxed only up to a maximum threshold, indexed to Social Security's Average Wage Index (AWI).

We follow the standard assumption that the incidence of the tax is entirely borne by workers. ${ }^{9,10}$ Relatively high earners are required to treat up to one half of their benefits as personal income subject to federal income taxation. Revenues from the taxation of benefits accrue to the trust fund.

Benefits are paid on a monthly basis, with the amount determined by the type of benefit, age when benefits are first claimed, and average wages over the worker's lifetime. Individuals can claim benefits on either their own work history or their spouse's work history. Spouses are generally entitled to one-half of their spouse's benefit while their spouse is alive and their spouse's full benefit after their spouse has died. ${ }^{11,12}$

Our objective in this paper is to explore hypothetical referendums in which people vote between pairs of potential Social Security reforms. In the real world however, such referendums are rare. In the United States (and many democracies) people vote for a bundle of policies in the form of representatives, and government processes make it easier to block than to pass legislation. ${ }^{13}$

More generally, numerous factors beyond net benefits may affect voting behavior e.g. the level of assets. Hurd (1989) shows that many people are over-annuitized and therefore, at the margin, would value Social Security less than the expected discounted present value of net benefits. Rangel (2003) shows how programs like Social Security, that benefit older generations, may help

\footnotetext{
${ }^{8}$ Luttmer and Samwick (2018) estimate the welfare costs of uncertainty about government policies, specifically, they estimate the risk premium from uncertainty about if, when, and how Social Security will be reformed, to be $10 \%$ of expected benefits.

${ }^{9}$ Empirical work has tended to support this assumption, see for example Brittain (1971). Although, recent more narrowly focused work has called it into question (Saez, Schoefer and Seim (2019)).

${ }^{10}$ Revenues are split between the Disability and Old Age Trust Funds at a rate of $2.37 \%$ and $10.03 \%$ respectively. Surpluses are "invested" in special issue Treasury bills available only to these trust funds, with the interest credited to the respective trust fund. The Disability and Old Age Trust Funds are legally separate entities. Following the majority of the literature, we treat them as if they were combined.

${ }^{11}$ Our goal in calculating benefits and taxes is not to exactly replicate the work of the Social Security actuaries. We make a few useful simplifying assumptions in order to utilize incomplete data on issues germane to our analysis of voting behavior. While they are close enough for our purposes, we also offer sensitivity analyses in Section 6, and in the Appendix.

${ }^{12}$ Although we focus mainly on the Net Present Value of lifetime and future benefits and taxes, people may have different ways of valuing the program or not know enough about the it to value it accurately. We view NPV as a sensible starting place, and the Hoover Institution Survey on Social Security showed that a majority of people generally understand the basics of social security. More information on these issues can be found in the Appendix.

${ }^{13}$ We simplify the analysis by ignoring the potential for strategic voting. See the Appendix for further discussion.
} 
sustain investment in goods that disproportionately benefit future generations, like education and a healthy environment. ${ }^{14,15}$

Our analysis proceeds in three steps: first, we calculate the "deal" a set of representative people get under current law and proposed reforms; second, we weight these "archetypes" by the share of the population they represent; third, we run hypothetical referendums under different assumptions on voting behavior.

We calculate the expected net present value of Social Security benefits and taxes for 112 different archetypes; on average each archetype represents less than $1 \%$ of the population. This approach is standard in analyzing how programs impact individuals, for example as in Steuerle and Quackenbush (2015) and Goda, Shoven, and Slavov (2018). Each archetype has three characteristics: a birth cohort, a marital status, and a work history. ${ }^{16}$

Birth cohorts begin in 1943 and are separated by 10 year intervals ending in $2013 .{ }^{17}$ Marital status is divided into single and married cohorts. An income cohort is a percentage of the AWI that the archetype's lifetime average earnings is equal to in the year the archetype turns 65 . For single archetypes, we use five different income cohorts (low, medium low, medium, medium high, and high income). For example, the low income cohort has lifetime average yearly earnings equal to $40 \%$ of the AWI in the year the archetype turns $65 .^{18}$ Workers retire probabilistically between the ages of 62 and $70 .{ }^{19,20}$

Work histories are calculated using the method of "scaled factors" that the SSA uses to construct hypothetical earnings histories (Clingman and Burkhalter (2017)), which generates earnings histories that start low in a worker's 20's, peak in their 40's, and gradually decline until retirement. In addition, this method has the effect of causing earnings over the life cycle of a cohort to fan out over time, as in Deaton and Paxson (1994). The nine income cohorts of married archetypes are defined by the pair of income cohorts into which the spouses fall. This procedure allows us to explore how the incentives interact and change along the three dimensions that most affect the level of taxes individuals pay and benefits they receive: age, earnings, and marital status.

Given characteristics of the archetypes, we calculate the expected net present value of taxes and benefits. We initially follow the 2019 Annual Report of the Board of Trustees intermediate assumptions. $^{21}$ Notably, we assume that real wages grow at a rate of $1.2 \%$ per year and an inflation rate of $2.6 \%$ per year. Table 2 presents a detailed list of assumptions. The factors with the largest impact on the actuarial deficit are the ratio of taxable payroll to total payroll

\footnotetext{
${ }^{14} \mathrm{We}$ add some more detailed intergenerational concerns to our analysis in the following sections, but view these as additional areas in which our work could be extended.

${ }^{15}$ We simplify the analysis by not examining so called, "file and suspend" strategies.

${ }^{16}$ Alternative approaches are discussed in the Appendix.

${ }^{17}$ Those alive and born prior to 1942 are included with the 1942 birth cohort when population shares are assigned.

${ }^{18}$ The income cohorts are defined as low $40 \%$, medium low $65 \%$, medium $100 \%$, medium high $145 \%$, and high $190 \%$.

${ }^{19}$ We use the SSA's data on new beneficiaries to calculate a distribution of retirement ages which vary by age cohort. We calculate a worker's expected NPV given each potential age, and take the average weighted by the probability a person in a given age cohort claims benefits at that age.

${ }^{20}$ About 3\% of the population age $60-89$ never recieve benefits. Of these individuals, $44 \%$ are infrequent workers, $37 \%$ are late-arriving immigrants, $11 \%$ are uncovered workers (mostly state and local government employees), and the remaining $7 \%$ die before receiving benefits. We ignore this issue for simplicity.

${ }^{21}$ The annual report from 2019 was recently released with a number of updated assumptions. The values are mostly the same or slightly changed. The largest difference is a decrease in the incidence of disability. Our sensitivity analysis suggests our results are not sensitive to the exact numbers used.
} 
and the rate at which life expectancy increases. We discount future payments and gross up past payments at a real rate of $2 \%$ per year to the present. ${ }^{22,23,24}$ Taxes and benefits that have not yet been paid or received are discounted by the probability that the archetype lives to pay or receive them respectively. We use survival probabilities from the most recent complete cohort life tables available from the SSA. ${ }^{25}$ The different sets of macroeconomic and demographic assumptions, SSA Intermediate, CBO and SSA High, do lead to important differences in referendum outcomes, discussed below in Section V and in the Appendix.

Table 2-: Alternative Economic and Demographic Assumptions

\begin{tabular}{cccc}
\hline Economic and Demographic Assumptions & SSA Intermediate & CBO & SSA High \\
\hline Real Wage Growth & 0.0121 & 0.013 & 0.006 \\
Taxable Ratio & 0.825 & 0.770 & 0.810 \\
Annual CPI Growth & 0.026 & 0.024 & 0.020 \\
Real Interest Rate & 0.025 & 0.023 & 0.020 \\
Unemployment Rate & 0.055 & 0.053 & 0.065 \\
Mortality Reduction & 0.008 & 0.012 & 0.012 \\
Net Immigration & 1.3 & 1.3 & 1 \\
Fertility Rate & 2 & 1.9 & 1.8 \\
\hline
\end{tabular}

note: The mortality reduction is measured as the annual reduction in central death rates. Net immigration is measured in millions of people.

After calculating the net present value, we attach to each archetype a population weight, i.e. its share of the population, calculated from the 2018 March Supplement to the Current Population Survey. We consider how differential voting patterns across archetypes could affect the hypothetical referendums. We assign to each archetype an "American" probability of voting, equal to the average share of the archetype that voted in recent elections ${ }^{26}$ and present interesting indicative results considering alternative assumptions on voter behavior below.

\section{Net Present Values for Archetypical Worker Beneficiaries}

Table 3 displays the expected net present value of Social Security benefits, taxes, and transfers for married archetypes. The transfers are generally large and variable. A 65 year old two earner couple in the lowest income cohort has a present value of benefits equal to 12 times their yearly earnings at $65(\$ 32,000)$, while a similar couple with two earners in the highest income cohort

\footnotetext{
${ }^{22}$ Steuerle and Quakenbush (2015) also use $2 \%$ per year.

${ }^{23}$ The SSA uses an estimate of the real interest rate received from Treasury Securities, which is projected at $2.5 \%$, to do present value calculations of the unfunded liabilities. Unlike the trust fund, people pay taxes on their savings, and so receive a lower real rate of return and may use a lower discount rate. Note also that values in our calculations are inflation adjusted and discounted by mortality probabilities. In future work we intend to examine heterogeneous discount rates.

${ }^{24}$ If the recent period of historically low real interest rates on government bonds continues, the actuarial deficit and the tax increases and benefit reductions necessary to close the deficit will be much larger.

${ }^{25}$ See SSA Actuarial Study 20.

${ }^{26}$ We use the November Supplement to the Current Population Survey.
} 
has a present value of benefits equal to about 6.5 times their yearly earnings $(\$ 151,000) .{ }^{27}$ The net transfers generally become more negative as income increases. Since taxes are proportional to earnings up to the cap, while benefits are a progressive function of average lifetime earnings, some intragenerational redistribution takes place: lower income cohorts tend to receive relatively good deals from Social Security, higher income cohorts generally do not. ${ }^{28}$

Table 3-: Lifetime Net Present Value of Transfers (LNPV), Discounted to Age 65, for Married Archetypes Assuming no Action on Unfunded Liabilities.

\begin{tabular}{rrrrrrrrrrr}
\multicolumn{10}{c}{$\$ 2019$ Thousands } \\
\hline & & & \multicolumn{8}{c}{ Income Cohorts } \\
& Pr & Low & Low & Med & Med & Med & High & High & High & High \\
& Sp & $\$ 0$ & Low & $\$ 0$ & Low & Med & $\$ 0$ & Low & Med & High \\
\hline & & & & & & & & & & \\
25 & Ben & 515.4 & 643.3 & 898.6 & 942.9 & 1121.6 & 1287.9 & 1287.9 & 1425.8 & 1607.8 \\
25 & Tax & 224.0 & 448.1 & 560.1 & 784.1 & 1120.2 & 1064.2 & 1288.2 & 1624.3 & 2128.4 \\
25 & Net & 291.3 & 195.3 & 338.5 & 158.8 & 1.4 & 223.7 & -0.3 & -198.5 & -520.6 \\
& & & & & & & & & & \\
45 & Ben & 391.2 & 486.6 & 682.1 & 715.2 & 848.4 & 977.6 & 977.6 & 1080.4 & 1216.1 \\
45 & Tax & 178.7 & 357.4 & 446.7 & 625.4 & 893.4 & 848.7 & 1027.4 & 1295.4 & 1697.4 \\
45 & Net & 212.5 & 129.2 & 235.4 & 89.8 & -45.0 & 128.9 & -49.8 & -215.0 & -481.4 \\
& & & & & & & & & & \\
65 & Ben & 319.0 & 395.0 & 563.5 & 587.1 & 697.6 & 794.6 & 794.8 & 878.9 & 984.2 \\
65 & Tax & 142.2 & 284.3 & 355.4 & 497.6 & 710.8 & 675.3 & 817.5 & 1030.7 & 1350.6 \\
65 & Net & 176.8 & 110.7 & 208.1 & 89.5 & -13.2 & 119.3 & -22.7 & -151.8 & -366.4 \\
\hline
\end{tabular}

note: Age categories are 10 year intervals centered on the indicated age. Pr and Sp indicate the income of the primary and secondary earners respectively.

One group that gains disproportionately from the program is single earner, married households. Even the highest earners get more out of Social Security than they pay in, due to the spousal benefit, generally $50 \%$ of their spouse's benefit. A one earner couple pays the same amount of lifetime taxes as a single individual with the same earnings. Due to real wage growth, younger workers both pay more in taxes and receive more in benefits than older workers. Increases in life expectancy also increase both expected taxes and expected benefits, since it is more likely that workers will live to pay, and receive, them respectively. In Table 3, since the expectation is taken given that the workers have lived to 65 , increases in life expectancy increase benefits more than taxes. Within the age cohorts, four of the six archetypes with two earners have expected benefits that are smaller than, or roughly equal to, expected taxes. In contrast, all single earner

\footnotetext{
${ }^{27}$ Bee and Mitchell (2017), correcting for underreporting of income, estimate median income for householders aged 65 and older was $\$ 44,400$, about $6 \%$ of the expected LNPV of benefits for 65 year olds where both spouses had median lifetime average earnings.

${ }^{28}$ Recent research has demonstrated that, in the United States, increases in life expectancy have been larger for high income individuals. Auerbach and et al. (2017) examine how this may attenuate the progressive features of Social Security.
} 
couples receive considerably more in benefits than in taxes over their lifetimes.

The graphs in Figure 1 demonstrate some of these patterns for single archetypes. The first panel shows how the LNPV changes as income increases for different age cohorts. As expected, the LNPV of the program is decreasing in income for all age cohorts. One of the most interesting features of the panel is that the lines cross. Young archetypes in the low income cohorts can expect a better deal than older archetypes in the same income cohort, while the opposite is true in high income cohorts, demonstrating the heterogeneity of interests within and across cohorts and the progressivity of the benefit formula. The second panel similarly shows how LNPV changes as age increases for different income cohorts.

Figure 1.

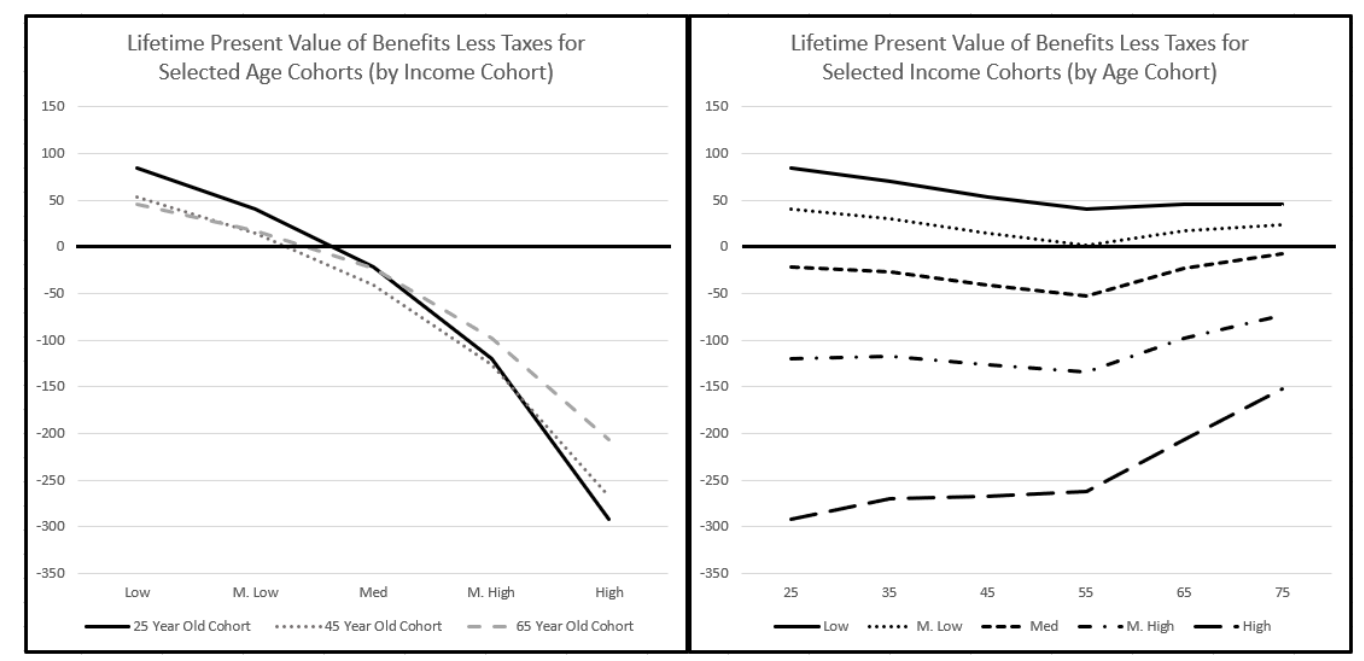

notes: The income cohorts are defined as a level of average lifetime earnings as a percent of the AWI. The cohorts "Low", "M. Low", "Med", "M. High", and "High" correspond to 40\%, 65\%, 100\%, 145\%, and 190\% of the AWI, respectively.

In contrast to Table 3 and Figure 1, Table 4 shows the expected net present value of taxes and benefits that will be paid and received after 2019. We refer to this as the Future NPV or FNPV. The LNPV and the FNPV are much the same for the 25 year old cohort. Archetypical workers in this cohort haven't received any benefits yet, and have almost all of their taxes left to pay. For older cohorts however, FNPV is very different than LNPV. Every archetype in the 45 year old and older cohorts has positive net future transfers, and from the second panel of Figure 2, which graphs Future NPV against age by income cohort, we see that only the highest income cohort still has a negative FNPV by age 35 . We believe that this at least partly explains the large support among voters for Social Security. Many people with a negative LNPV have a positive FNPV. As we will demonstrate in analyzing hypothetical referendums, the political salience of this fact is greatly amplified by the voting patterns prevalent in the United States. 
Table 4-: Net Present Value of Future Transfers (FNPV), Discounted to Age 65, for Married Archetypes Assuming no Action on Unfunded Liabilities.

\begin{tabular}{rrrrrrrrrrr}
\multicolumn{10}{c}{$\$ 2019$ Thousands } \\
\hline & & \multicolumn{10}{c}{ Income Cohorts } \\
Age & Pr & Low & Low & Med & Med & Med & High & High & High & High \\
& Sp & $\$ 0$ & Low & $\$ 0$ & Low & Med & $\$ 0$ & Low & Med & High \\
\hline & & & & & & & & & & \\
25 & Ben & 515.4 & 643.3 & 898.6 & 942.9 & 1121.6 & 1287.9 & 1287.9 & 1425.8 & 1607.8 \\
25 & Tax & 214.7 & 429.4 & 536.8 & 751.5 & 1073.6 & 1019.9 & 1234.6 & 1556.7 & 2039.8 \\
25 & Net & 300.6 & 213.9 & 361.8 & 191.4 & 48.1 & 268.0 & 53.3 & -130.9 & -432.0 \\
& & & & & & & & & & \\
45 & Ben & 391.2 & 486.6 & 682.1 & 715.2 & 848.4 & 977.6 & 977.6 & 1080.4 & 1216.1 \\
45 & Tax & 79.4 & 158.7 & 198.4 & 277.8 & 396.8 & 377.0 & 456.4 & 575.4 & 754.0 \\
45 & Net & 311.8 & 327.9 & 483.7 & 437.4 & 451.5 & 600.6 & 521.2 & 505.0 & 462.1 \\
& & & & & & & & & & \\
65 & Ben & 289.0 & 357.9 & 510.3 & 531.3 & 631.8 & 719.9 & 720.1 & 796.0 & 891.6 \\
65 & Tax & 1.1 & 2.3 & 2.8 & 4.0 & 5.7 & 5.4 & 6.6 & 8.3 & 10.8 \\
65 & Net & 287.8 & 355.6 & 507.4 & 527.4 & 626.1 & 714.5 & 713.5 & 787.7 & 880.8 \\
& & & & & & & & & & \\
\hline
\end{tabular}

note: Age categories are 10 year intervals centered on the indicated age. Pr and Sp indicate the income of the primary and secondary earners respectively.

\section{Economic and Demographic Assumptions, Archetypical Reforms, and Voting Proclivities}

\section{A. Economic and Demographic Assumptions}

All of our previous calculations assume that the program continues in its current form, without any change in benefits or taxes. As we have shown, however, this is not possible under any reasonable assumptions, given the immense unfunded liabilities. ${ }^{29}$ Given the official economic and demographic assumptions, there are only two options to return Social Security to solvency: either taxes can be increased or outlays reduced from their growing projected levels. ${ }^{30}$ In practice, however, specific reform proposals may combine these options, phase changes in over time, or target specific parts of the population. The specifics of potential reforms have large impacts on who bears the cost of returning the program to financial stability. We calculate LNPV and FNPV under seven different archetypical reforms, explore who fares better and worse under the reformed rules, and predict which reforms would be preferred by whom. To make the archetypical reforms comparable, we choose reforms that close (approximately) the actuarial deficit, as estimated by

\footnotetext{
${ }^{29} \mathrm{~A}$ higher long-term growth rate would help considerably, but it is unlikely it could be high enough, or long enough, to eliminate the large majority of the unfunded liabilities.

${ }^{30} \mathrm{~A}$ higher long-term growth rate could help considerably, but it is unlikely it would be high enough for long enough to eliminate the large majority of the unfunded liabilities.
} 
Figure 2 .

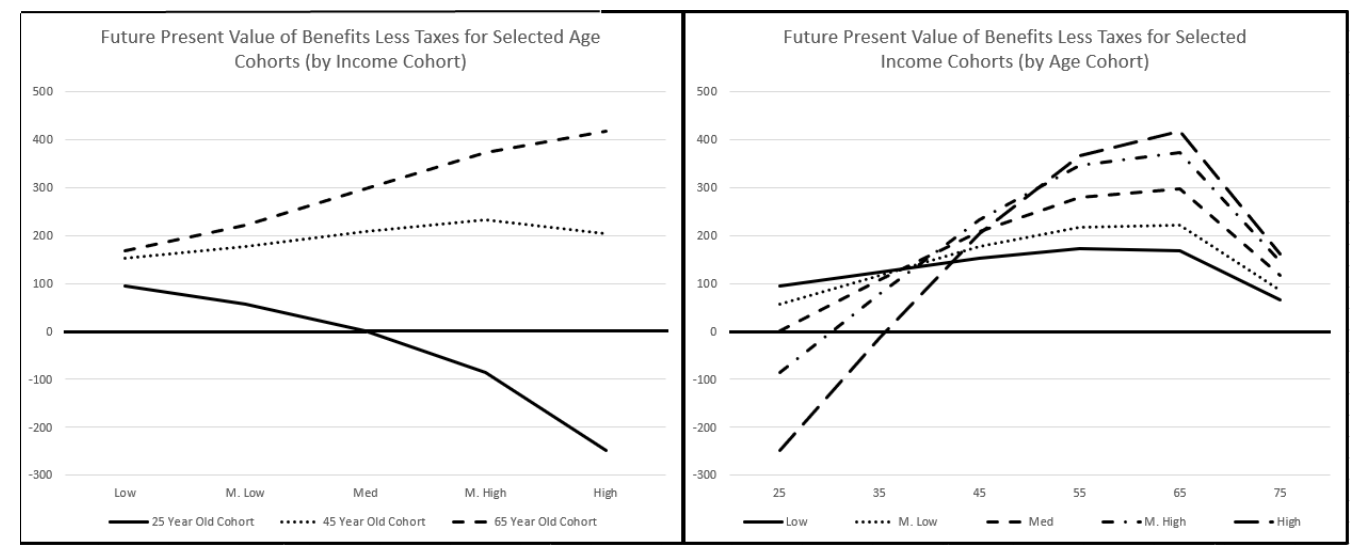

notes: The income cohorts are defined as a level of average lifetime earnings as a percent of the AWI. The cohorts "Low", "M. Low", "Med", "M. High", and "High" correspond to 40\%, 65\%, 100\%, 145\%, and 190\% of the AWI; respectively.

the SSA and, alternatively, by the CBO. Although reforms do not necessarily need to close the 75 year deficit, we focus on reforms that do. The 1983 reforms were putatively designed with that purpose, and much of the discussion from the SSA revolves around this benchmark of financial stability. ${ }^{31}$

We perform our analysis under all three sets of assumptions listend in Table 2; our calculations, except where explicitly stated otherwise, use the SSA's intermediate assumptions, which it deems most likely. Some assumptions, e.g. real wage growth, directly affect NPV calculations, while others, e.g. net immigration, affect them through the size of the actuarial deficit, and therefore the size of the reforms necessary to close it. Notably, the CBO projects a higher share of wages above the taxable threshold, and bigger increases in life expectancy than does the SSA, which leads the CBO to a significantly larger deficit. ${ }^{32}$

\section{B. Archetypical Reforms}

Table 5 lists the year each reform takes effect and the "size" of the reform under all three sets of assumptions. For example, the first row shows that an across the board $17 \%$ benefit cut, ${ }^{33}$ enacted in 2019, would approximately close the 75 year actuarial deficit under the SSA's intermediate cost assumptions. The reforms listed in the table are an immediate benefit cut (2019), a benefit cut in the year the trust fund is exhausted (2035), an immediate (2019) payroll tax increase, a payroll tax increase when the trust fund becomes exhausted (2035), indexing

\footnotetext{
${ }^{31}$ Thus far there has been great resistance to explicit general revenue financing of social security, which would open the door to debt finance, with its additional intergenerational considerations. Our survey confirms this observation. Raising income taxes had far less support than raising payroll taxes among respondents. See Table 1.

${ }^{32}$ The assumed fertility rate is a prime determinant of the ratio of workers to beneficiaries over the long run. The recent fertility trends are well below the assumed 2.0, which is approximately the replacement rate (Mathews and Hamilton (2019)).

${ }^{33}$ All references to "benefit cuts" are relative to the baseline of growing real benefits.
} 
initial benefits by prices rather than by wages, and finally, benefit cuts that exclude current retirees and those near retirement.

Table 5-: Archetypal Reforms That Approximately Close the 75 Year Actuarial Deficit

\begin{tabular}{lccccc}
\hline \multicolumn{1}{c}{ Reform Type } & Effective Year & Abbreviation & Int Cost & CBO & High Cost \\
\hline Benefit & 2019 & Ben19 & $17 \%$ & $25 \%$ & $32.5 \%$ \\
Reductions & 2035 & Ben35 & $23 \%$ & $29 \%$ & $37.0 \%$ \\
& & & & & \\
Exc. Near & 2019 & B19N & $20 \%$ & $32 \%$ & $38.6 \%$ \\
Retirement & 2035 & B35N & $28 \%$ & $35 \%$ & $44 \%$ \\
& & & & & \\
Tax Increases & 2019 & Tax19 & $2.70 \mathrm{pp}$ & $4.37 \mathrm{pp}$ & $5.40 \mathrm{pp}$ \\
& 2035 & Tax35 & $3.65 \mathrm{pp}$ & $6.06 \mathrm{pp}$ & $7.48 \mathrm{pp}$ \\
Price Indexing & 2019 & Price & & & \\
\hline
\end{tabular}

notes: Price indexing can refer to several different reform proposals. We mean indexing increases in the PIA formula bend points to the CPI instead of the AWI. Price Indexing does not close the actuarial deficit under the CBO or High Cost assumptions. In the case of the $\mathrm{CBO}$ assumptions, we add to price indexing an increase in the full retirement age. We do not include price indexing when using the high cost assumptions because it is not clear what else would have to be added. The size of reforms for the High Cost case were imputed based on the estimate of the actuarial deficit. Solving the 75 year deficit does not necessarily imply that the trust fund will be fully solvent in each year. We assume that the trust fund can borrow against future savings or revenue increases in such a way that the actuarial deficit is unchanged.

Earnings used to calculate the AIME, bend points in the PIA formula, and the taxable maximum are all indexed to the SSA's Average Wage Index (AWI). ${ }^{34}$ The reform proposal immediately (2019) indexes future changes in the bend points to the CPI-W. Functionally, it is a reduction to the scheduled growth of real benefits for workers under age 60, but, since years prior to 2019 would still be indexed by wages, the initial effect would be small but would grow over time. Price indexing affects those near retirement very little, and those the furthest away from claiming benefits the most, but no recipient's benefits would be reduced relative to today's real levels. Since the CBO estimates a larger actuarial deficit, price indexing the bend points alone will not be sufficient to close the actuarial deficit. To close the larger deficit, when using the CBO's assumptions, we add a three year increase in the full retirement age (FRA) to price indexing. ${ }^{35}$

\section{C. $\quad$ Voting Patterns}

Just as important as what people are likely to vote for is how likely they are to vote. Table 6 shows voting proclivities by age for the United States and several European countries. Notice

\footnotetext{
${ }^{34}$ To calculate the AWI, the SSA measures changes in average wages using data on wages subject to federal income taxes and contributions to deferred compensation plans. It differs from the BLS measure of average wage increases, which is estimated from the National Compensation Survey which surveys establishments.

${ }^{35}$ The increase is phased in by adding two months per year to each individual's FRA, beginning with those first eligible for benefits in 2023, when the most recent increases in the FRA are scheduled to end.
} 
that in all countries turnout is lowest among the 25 year old cohort. But, in the United States and Great Britain, older cohorts are almost twice as likely as the 25 year olds to participate, while in the rest of these countries older cohorts are less than one and a half times as likely. ${ }^{36}$

Table 6-: Voter Turnout Compared Across Countries

\begin{tabular}{lccccccccc}
\hline Age & U.S. & BE & DE & DK & ES & G.B. & IT & NL & NO \\
\hline 25 & $34 \%$ & $83 \%$ & $66 \%$ & $78 \%$ & $61 \%$ & $43 \%$ & $74 \%$ & $72 \%$ & $65 \%$ \\
35 & $42 \%$ & $85 \%$ & $73 \%$ & $90 \%$ & $71 \%$ & $58 \%$ & $86 \%$ & $79 \%$ & $79 \%$ \\
45 & $50 \%$ & $87 \%$ & $80 \%$ & $93 \%$ & $78 \%$ & $71 \%$ & $90 \%$ & $82 \%$ & $85 \%$ \\
55 & $58 \%$ & $91 \%$ & $83 \%$ & $94 \%$ & $83 \%$ & $78 \%$ & $91 \%$ & $86 \%$ & $89 \%$ \\
65 & $64 \%$ & $90 \%$ & $86 \%$ & $96 \%$ & $85 \%$ & $83 \%$ & $90 \%$ & $88 \%$ & $90 \%$ \\
75 & $64 \%$ & $85 \%$ & $86 \%$ & $93 \%$ & $80 \%$ & $87 \%$ & $78 \%$ & $87 \%$ & $89 \%$ \\
\hline
\end{tabular}

Source: Current Population Survey and European Social Survey, Author's Calculations. Age Cohorts are 10 year intervals centered on the age indicated. The U.S. percentages are the average as described in the text. The European percentages are the share of survey respondents who reported voting in the, "most recent national election." The most recent national election was not necessarily in the same year for different countries. National elections may also take very different forms in different countries.

\section{Main Results on Reform Referendums}

Table 7 presents the share of each of our population archetypes with positive and negative NPV, assuming no action is taken on the unfunded liabilities, i.e. voters presume benefits are paid and taxes are collected as currently legislated. ${ }^{37}$ While almost $40 \%$ of the population has a negative lifetime value of the program, only about $10 \%$ of the population has a negative future value of the program. ${ }^{38}$ The characteristics that have the biggest impact on LNPV and FNPV are age and income. As expected, due to the progressive nature of the benefit formula, lower income cohorts tend to have higher NPV. A striking feature of the table however, is that the share of a cohort with positive LNPV (but not FNPV) is larger for younger cohorts. This occurs because of the interaction of differential discounting due to survival probabilities and the timing of taxes and benefits. ${ }^{39}$

The status quo, as described in Table 7, is always preferred to any of the archetypical reforms. Any reform that improves Social Security's financial outlook will necessarily make many worse off, in terms of lower projected benefits or higher taxes, compared to the impossible unfunded

\footnotetext{
${ }^{36}$ Turnout in the 2018 midterm U.S. elections, while very high and apparently especially so for younger voters, by midterm election standards, was far short of turnout for presidential elections. Young voter turnout also rose disproportionately in President Obama's 2008 and 2012 elections. Our base American voting proclivities may already include a higher than average young voter turnout.

${ }^{37}$ What would happen exactly is not well defined. See the Appendix for further information.

${ }^{38}$ The exact shares are sensitive to the discount rate used. Higher discount rates emphasize taxes over benefits, because they are received first, which leads to a larger share of the population having negative NPV and FNPV. Under any reasonable discount rate however, much of the population has a positive FNPV.

${ }^{39}$ See the Appendix for a detailed explanation of the interaction.
} 
Table 7-: Distribution of Net Present Value Discounted to 2019 Assuming No Action on Unfunded Liabilities.

\begin{tabular}{|c|c|c|c|c|c|}
\hline & Turnout & $\mathrm{LNPV}>0$ & $\overline{\mathrm{LNPV}<0}$ & $\overline{F N P V}>0$ & $\overline{F N P V<0}$ \\
\hline Overall & $100.0 \%$ & $46.6 \%$ & $53.4 \%$ & $88.7 \%$ & $11.3 \%$ \\
\hline \multicolumn{6}{|c|}{ Marital Status } \\
\hline Single & $26.6 \%$ & $38.4 \%$ & $61.6 \%$ & $76.3 \%$ & $23.7 \%$ \\
\hline Married & $73.4 \%$ & $49.6 \%$ & $50.4 \%$ & $93.2 \%$ & $6.8 \%$ \\
\hline \multicolumn{6}{|c|}{ Age Cohorots } \\
\hline 25 & $18.5 \%$ & $44.7 \%$ & $55.3 \%$ & $57.9 \%$ & $42.1 \%$ \\
\hline 35 & $17.8 \%$ & $34.2 \%$ & $65.8 \%$ & $80.3 \%$ & $19.7 \%$ \\
\hline 45 & $16.6 \%$ & $25.5 \%$ & $74.5 \%$ & $100.0 \%$ & $0.0 \%$ \\
\hline 55 & $17.6 \%$ & $33.0 \%$ & $67.0 \%$ & $100.0 \%$ & $0.0 \%$ \\
\hline 65 & $15.4 \%$ & $58.1 \%$ & $41.9 \%$ & $100.0 \%$ & $0.0 \%$ \\
\hline 75 & $14.1 \%$ & $94.1 \%$ & $5.9 \%$ & $100.0 \%$ & $0.0 \%$ \\
\hline \multicolumn{6}{|c|}{ Income Cohorts (Single Archetypes) } \\
\hline Low & $12.5 \%$ & $81.6 \%$ & $18.4 \%$ & $100.0 \%$ & $0.0 \%$ \\
\hline M. Low & $3.9 \%$ & $0.3 \%$ & $99.7 \%$ & $100.0 \%$ & $0.0 \%$ \\
\hline Medium & $4.1 \%$ & $0.0 \%$ & $100.0 \%$ & $45.7 \%$ & $54.3 \%$ \\
\hline M. High & $2.6 \%$ & $0.0 \%$ & $100.0 \%$ & $43.1 \%$ & $56.9 \%$ \\
\hline High & $3.5 \%$ & $0.0 \%$ & $100.0 \%$ & $24.9 \%$ & $75.1 \%$ \\
\hline
\end{tabular}

${ }^{1}$ Age Categories are 10 year intervals centered on the age indicated. Columns labeled LNPV are the Net Present Value of Transfers, i.e. benefits less taxes. Columns labeled FNPV treat past payments and benefits as sunk.

scenario. In any hypothetical referendum, if doing nothing is considered a feasible option, doing nothing will win. Over $90 \%$ of potential voters have positive FNPV. Almost all married couples and singles over 45 have a positive FNPV. The people with negative FNP are concentrated in young high income archetypes. This emphasizes the critical nature of framing the alternatives for voters and potential voters. If a reform is to have any hope of passing, people have to understand what will happen if reform is not enacted, and what types of reforms will be necessary. This is underscored by the results of the Hoover Institution YouGov Survey on Social Security which show that although $67 \%$ of respondents agreed that Social Security is heading for a financial crisis in the future, $43 \%$ also agreed that minor changes could fix any problems the program faces. 


\section{A. Hypothetical Referenda}

A summary of the outcomes of all the pairwise hypothetical referendums ${ }^{40}$ between archetypical reforms, under the SSA's intermediate assumptions, is presented in Table 8. We assume that voters in each archetype calculate their expected FNPV under both policies, and the share of the archetype that has historically participated in elections votes for the reform which gives them a greater FNPV. In our analysis of the Hoover Survey on Social Security we found that a payroll tax increase was favored by $38 \%$ of respondents, with $33 \%$ opposed. The only option more preferred was reducing or slowing the growth of benefits for high income individuals, which $51 \%$ supported. Only $15 \%$ of respondents favored slowing the growth of benefits for current retirees. The results of our hypothetical referenda are consistent with these data, at least in the sense that payroll tax increases tend to receive support. In Table 8, notice that a tax increase when the trust fund is exhausted in 2035 never loses a referendum in which it is an option, under the SSA assumptions.

Table 8-: Pairwise Hypothetical Referendums: SSA Intermediate

\begin{tabular}{|c|c|c|c|c|c|c|c|}
\hline & Ben18 & $\mathrm{B} 18 \mathrm{~N}$ & Tax18 & Price & Ben34 & B34N & Tax34 \\
\hline Ben18 & - & $\mathrm{W}^{1}$ & $\mathrm{~L}$ & $\bar{L}$ & $\mathrm{~L}$ & $\mathrm{~L}$ & $\bar{L}$ \\
\hline B18N & & - & $\mathrm{L}$ & $\mathrm{L}$ & W & $\mathrm{L}$ & $\mathrm{L}$ \\
\hline Tax18 & & & - & $\mathrm{L}$ & W & $\mathrm{L}$ & $\mathrm{L}$ \\
\hline Price & & & & - & $\mathrm{W}$ & $\mathrm{L}$ & $\mathrm{L}$ \\
\hline Ben34 & & & & & - & $\mathrm{L}$ & $\mathrm{L}$ \\
\hline B34N & & & & & & - & $\mathrm{L}$ \\
\hline Tax34 & & & & & & & - \\
\hline
\end{tabular}

note: "W" ("L") indicates that the row wins (loses) a hypothetical referendum against the column. The abbreviations for the archetypal reforms are listed in Table 5. Voters participate at the historical levels of American voters.

Another striking feature of Table 8 is a violation of transitivity among the pairwise referendums. Notice that Ben18 wins against Ben18N, and that Ben18N wins against Ben34. Transitivity would imply that Ben18 wins against Ben34, but this is not the case! Ben18 loses to Ben34 because the 55 and older cohorts prefer having some years of full benefits and harsher benefit cuts than a milder benefit cut applied to all future benefits. But when the 65 and 75 year old cohorts are excluded from the immediate benefit cut in Ben18N versus Ben34, the 65 and 75 year old cohorts switch to support immediate reform so that Ben18N wins. Ben18 beats Ben18N however, because except for the 65 and 75 year old cohorts who get full benefits under Ben18N, everyone is choosing between a large benefit reduction and a smaller one. There are more participating voters in the 55 and younger cohorts than in the 65 and 75 year old cohorts, so Ben18 wins. The often discussed theoretical possibility of transitivity violations or voting cycles,

\footnotetext{
${ }^{40}$ As previously mentioned, there could be more complex voting procedures that bundle multiple policies together.
} 
among sets of pairwise comparisons, occurs in this realistic case given the actual distribution of preferences over the estimated effects of the referenda on the financial deal different voters can expect to receive.

However, the picture changes in important ways when instead of using the SSA's assumptions we use the CBO's, shown in Table A4. The delayed reforms are now implemented in 2031, due to the earlier trust fund exhaustion date. Two referendums have different outcomes. In particular, while a delayed tax increase won every referendum in which it was on option in Table 8, in Table A4 Ben34N wins against Tax34. The most preferred option among delayed reforms depends on the assumptions, ${ }^{41}$ and the voting cycle discussed above does not occur under the CBO's assumptions, due to the reversed outcome of an immediate benefit cut versus a delayed benefit cut. In this referendum, older cohorts are choosing between a small benefit cut that applies to all future benefits and a larger benefit cut that applies to only some future benefits. For the 55 year olds in particular, the larger cuts and the earlier forcing date under the CBO's assumptions make the delayed benefit cut less attractive, and the 55 year olds change their vote.

Table 9-: Pairwise Hypothetical Referendums: CBO Long-Term Budget Outlook Assumptions

\begin{tabular}{|c|c|c|c|c|c|c|c|}
\hline & Ben18 & $\mathrm{B} 18 \mathrm{~N}$ & Tax18 & Price & Ben31 & B31N & Tax31 \\
\hline Ben18 & - & $\mathrm{W}^{1}$ & $\mathrm{~L}$ & $\mathrm{~L}$ & W & $\mathrm{L}$ & $\mathrm{L}$ \\
\hline B18N & & - & L & $\mathrm{L}$ & W & $\mathrm{L}$ & $\mathrm{L}$ \\
\hline Tax18 & & & - & $\mathrm{L}$ & W & $\mathrm{L}$ & $\mathrm{L}$ \\
\hline Price & & & & - & W & $\mathrm{L}$ & $\mathrm{L}$ \\
\hline Ben31 & & & & & - & $\mathrm{L}$ & $\mathrm{L}$ \\
\hline $\mathrm{B} 31 \mathrm{~N}$ & & & & & & - & W \\
\hline Tax31 & & & & & & & - \\
\hline
\end{tabular}

notes: "W" ("L") indicates that the row wins (loses) the hypothetical referendum against the column. Voters participate at the historical levels of American voters.

Returning to the SSA's intermediate assumptions, we examine one of these referenda in more detail. Table 10 shows the outcome of a benefit cut in 2019 compared to a benefit cut in 2035 broken down by age and compared across three different potential voting patterns. The top panel shows the outcome under different voting proclivities, and the bottom panel shows the percentage of the total population in each age cohort that votes. In this case, preference for one reform over the other is entirely determined by age. In the first column, voters participate at the historical levels of American voters. Relatively older voters are more likely to participate, so their preferences are more strongly represented, and the delayed benefit cut wins. When all eligible voters participate, the immediate benefit cut wins. Even though more people prefer the immediate benefit cut, the historical voting patterns would reject it. If younger Americans could just be induced to participate at the level of their European counterparts, the immediate

${ }^{41}$ Section $\mathrm{V}$ discusses this particular referendum in more detail. 
reform would win. The third column Table 10 shows the results using German voting patterns, where young voter relative turnout is higher than in the United States, but lower than in other European countries. The immediate benefit cut narrowly wins. ${ }^{42}$ We emphasize that what changes between the columns of Table 10 is who votes, not how people vote. Building a coalition to support immediate reform will require convincing voters to turnout, especially young American voters who historically have been less likely to do so.

Table 10-: Hypothetical Referendum Comparing a Benefit Cut in $2019(17 \%)$ to a Benefit Cut in 2035 (23\%).

\begin{tabular}{lcccccc}
\multicolumn{7}{c}{ Referendum Outcome } \\
Share Voting & American & All Eligible & German \\
& $35.7 \%$ & $100.0 \%$ & $57.0 \%$ \\
& $1 \mathrm{P} 2$ & $2 \mathrm{P} 1$ & $1 \mathrm{P} 2$ & $2 \mathrm{P} 1$ & $1 \mathrm{P} 2$ & $2 \mathrm{P} 1$ \\
& $45.0 \%$ & $55.0 \%$ & $52.9 \%$ & $47.1 \%$ & $51.0 \%$ & $49.0 \%$ \\
\multicolumn{7}{c}{ By Age Cohort } \\
Age Cohorts & U.S. All & DE & $1 \mathrm{P} 2$ & Indiff & $2 \mathrm{P} 1$ \\
\hline 25 & $4.5 \%$ & $18.5 \%$ & $9.4 \%$ & $100.0 \%$ & $0.0 \%$ & $0.0 \%$ \\
35 & $5.4 \%$ & $17.8 \%$ & $9.7 \%$ & $100.0 \%$ & $0.0 \%$ & $0.0 \%$ \\
45 & $5.8 \%$ & $16.6 \%$ & $8.7 \%$ & $100.0 \%$ & $0.0 \%$ & $0.0 \%$ \\
55 & $7.2 \%$ & $17.6 \%$ & $10.3 \%$ & $0.0 \%$ & $0.0 \%$ & $100.0 \%$ \\
65 & $6.7 \%$ & $15.4 \%$ & $9.8 \%$ & $0.0 \%$ & $0.0 \%$ & $100.0 \%$ \\
75 & $6.0 \%$ & $14.1 \%$ & $8.0 \%$ & $0.0 \%$ & $0.0 \%$ & $100.0 \%$ \\
\hline
\end{tabular}

note: Read "1P2" as, option 1, a benefit cut in 2019, is preferred to option 2, a benefit cut in 2035. Age Categories are 10 year intervals centered on the age indicated. 18 and 19 year olds are included although their age cohort is not shown for the sake of brevity.

\section{B. Intergenerational Considerations}

Since the burden of many reforms, especially the delayed reforms, falls heavily on those who are too young to vote, we introduce 15 and 5 year old archetypes to examine how accounting for their interests may change the outcomes of referendums. A tax increase in 2035, for example, only affects archetypes in the 45 year old and younger cohorts. Moreover, the 35 and 25 year old cohorts will pay the higher tax rate for only part of their working life. The 15 and 5 year old cohorts will have all or almost all of their earnings taxed at the higher rate, but only the 18 and 19 year olds are eligible to vote. In our referendums so far, workers have only considered

\footnotetext{
${ }^{42}$ The results are much the same using voting patterns from other European countries.
} 
their own FNPV when choosing which reform to support. Forward thinking parents however, may consider both their own FNPV and their children's when making their choices. ${ }^{43}$

Consider a hypothetical referendum comparing price indexing of bend points to a benefit cut in 2035 that excludes those who will have retired or will be close to retirement in that year, (Table 11). Price indexing loses the referendum by eight points assuming historical voting patterns. We split each archetype into a new archetype with children and an otherwise identical archetype without children. Archetypes with children have FNPV equal to the sum of the Adult's FNPV and the FNPV of their children. ${ }^{44}$ Price indexing goes from losing to winning handily when parents consider their children's FNPV. The largest shifts come from middle aged cohorts, but a small number of even the oldest cohorts are caregivers. ${ }^{45,46}$

Table 11-: Comparison of a Hypothetical Referendum Comparing Price Indexing of Bend Points to a Benefit Cut in 2035 That Does Not Affect Age Cohorts Near Retirement, With and Without Parents Considering Their Children's FNPV.

\begin{tabular}{|c|c|c|c|c|c|c|c|c|}
\hline & \multicolumn{4}{|c|}{ American Voting Proclivities } & \multicolumn{4}{|c|}{ Parent's Net FNPV with Children } \\
\hline & Share & $1 \mathrm{P} 2$ & Indiff & $2 \mathrm{P} 1$ & Share & $1 \mathrm{P} 2$ & Indiff & $2 \mathrm{P} 1$ \\
\hline & Voting & & & & Voting & & & \\
\hline Overall & $36.1 \%$ & $28.9 \%$ & $35.2 \%$ & $35.9 \%$ & $36.1 \%$ & $42.6 \%$ & $32.3 \%$ & $25.1 \%$ \\
\hline & & & & By Age & Cohort & & & \\
\hline 15 & $0.6 \%$ & $100.0 \%$ & $0.0 \%$ & $0.0 \%$ & $0.6 \%$ & $100.0 \%$ & $0.0 \%$ & $0.0 \%$ \\
\hline 25 & $4.5 \%$ & $100.0 \%$ & $0.0 \%$ & $0.0 \%$ & $4.5 \%$ & $100.0 \%$ & $0.0 \%$ & $0.0 \%$ \\
\hline 35 & $5.4 \%$ & $100.0 \%$ & $0.0 \%$ & $0.0 \%$ & $5.4 \%$ & $100.0 \%$ & $0.0 \%$ & $0.0 \%$ \\
\hline 45 & $5.8 \%$ & $0.0 \%$ & $0.0 \%$ & $100.0 \%$ & $5.8 \%$ & $35.9 \%$ & $0.0 \%$ & $64.1 \%$ \\
\hline 55 & $7.2 \%$ & $0.0 \%$ & $0.0 \%$ & $100.0 \%$ & $7.2 \%$ & $25.5 \%$ & $0.0 \%$ & $74.5 \%$ \\
\hline 65 & $6.7 \%$ & $0.0 \%$ & $100.0 \%$ & $0.0 \%$ & $6.7 \%$ & $9.7 \%$ & $90.3 \%$ & $0.0 \%$ \\
\hline 75 & $6.0 \%$ & $0.0 \%$ & $100.0 \%$ & $0.0 \%$ & $6.0 \%$ & $6.6 \%$ & $93.4 \%$ & $0.0 \%$ \\
\hline
\end{tabular}

note: Age Categories are 10 year intervals centered on the age indicated. Read "1P2" as option 1 is preferred to option 2. In this referendum, the benefit cut in 2035 does not affect those who are near retirement in 2035 specifically the 45 year old and older cohorts.

Consider an alternative representation of the interests of the young. Imagine that a voting trust $^{47}$ is established for children too young to vote, but who nevertheless have a large stake in

\footnotetext{
${ }^{43}$ More generally, Social Security may be offset, at least in part, by reduced private intergenerational transfers, so called Ricardian Equivalence. (Barro, 1974).

${ }^{44}$ The FNPV of the children is weighted by the average number of children per household with children in that archetype. We do not account for expectations of additional future children.

${ }^{45}$ We assume here that parents only consider the preferences of their children that are too young to vote for themselves. Adult children or children people expect to have in the future are not included in these calculations for simplicity. Adding adult children would accentuate the effect.

${ }^{46}$ See the Appendix for intergenerational concerns in the opposite direction.

${ }^{47}$ Voting trusts are instruments that transfer the right to vote shares of a company to a trustee, while still maintaining
} 
Social Security and its future. Independent trustees could be instructed to represent the best interests of children in referendums that could have potentially large impacts on their future well being. We constrain the trust to vote with the average population probability of voting. ${ }^{48}$ Price indexing defeats a delayed benefit cut (Table 12), with a margin of victory is even wider than when parents consider their children's FNPV, as some parents now have their vote canceled out by their children.

Table 12-: Hypothetical Referendum Comparing Price Indexing of Bend Points to a Benefit Cut in 2035 That Only Affect the 35 Year Old and Younger Cohorts. Vote in Trust

\begin{tabular}{|c|c|c|c|c|c|c|c|c|}
\hline & \multicolumn{4}{|c|}{ American Voting Proclivities } & \multicolumn{4}{|c|}{ Vote in Trust } \\
\hline & Share & $1 \mathrm{P} 2$ & Indiff & $\overline{2} \mathrm{P} 1$ & Share & 1P2 & Indiff & $2 \mathrm{P} 1$ \\
\hline & Voting & & & & Voting & & & \\
\hline Overall & $36.1 \%$ & $28.9 \%$ & $35.2 \%$ & $35.9 \%$ & $47.1 \%$ & $45.5 \%$ & $27.0 \%$ & $27.6 \%$ \\
\hline & By Age & $\mathrm{Col}$ & & & & & & \\
\hline 5 & $0.0 \%$ & - & - & - & $6.0 \%$ & $100.0 \%$ & $0.0 \%$ & $0.0 \%$ \\
\hline 15 & $0.6 \%$ & $100.0 \%$ & $0.0 \%$ & $0.0 \%$ & $5.6 \%$ & $100.0 \%$ & $0.0 \%$ & $0.0 \%$ \\
\hline 25 & $4.5 \%$ & $100.0 \%$ & $0.0 \%$ & $0.0 \%$ & $4.5 \%$ & $100.0 \%$ & $0.0 \%$ & $0.0 \%$ \\
\hline 35 & $5.4 \%$ & $100.0 \%$ & $0.0 \%$ & $0.0 \%$ & $5.4 \%$ & $100.0 \%$ & $0.0 \%$ & $0.0 \%$ \\
\hline 45 & $5.8 \%$ & $0.0 \%$ & $0.0 \%$ & $100.0 \%$ & $5.8 \%$ & $0.0 \%$ & $0.0 \%$ & $100.0 \%$ \\
\hline 55 & $7.2 \%$ & $0.0 \%$ & $0.0 \%$ & $100.0 \%$ & $7.2 \%$ & $0.0 \%$ & $0.0 \%$ & $100.0 \%$ \\
\hline 65 & $6.7 \%$ & $0.0 \%$ & $100.0 \%$ & $0.0 \%$ & $6.7 \%$ & $0.0 \%$ & $100.0 \%$ & $0.0 \%$ \\
\hline 75 & $6.0 \%$ & $0.0 \%$ & $100.0 \%$ & $0.0 \%$ & $6.0 \%$ & $0.0 \%$ & $100.0 \%$ & $0.0 \%$ \\
\hline
\end{tabular}

note: Age Categories are 10 year intervals centered on the age indicated. Read "1P2" as option 1 is preferred to option 2. In this referendum, the benefit cut in 2035 does not affect those who are near retirement in 2035 specifically the 45 year old and older cohorts.

\section{Endogenous Participation}

In many referendums, a number of archetypes, making up a significant percentage of the population, are exactly indifferent between the competing options, because the effects on their future FNPV is identical. For example, some retirees or those near retirement age would have no change in their benefits or taxes under either option under consideration. We can think of the people in these archetypes as either splitting evenly between the two reforms, or alternatively as not participating at all. If we classify the indifferent population as not participating, then

control of the shares and the rights associated with it, for example the right to receive dividends. They are sometimes used in closely held corporations where giving one or a few people control is advantageous. Trusts also vote shares for minor children.

${ }^{48}$ If the trust votes for $100 \%$ of young persons, the interests of the young dominate, unless older voters increase their voting proportionally in response. Older voters would not be likely to allow such a vehicle to vote in greater proportion than the rest of the population. 
even though the share of each archetype that could vote is given exogenously, whether or not the archetype participates in the referendum at all is endogenous to the reforms under consideration. Moomau and Morton (1992) find that voters in a local referendum not only understood the implied financial impacts of a property tax change proposal, but also that people who would be impacted more by the proposal were more likely to vote. We explore this kind of endogenous participation by calculating an inertia of inattention threshold for each archetype where, if the change in FNPV between the two policies is less than the maximum of $\$ 10,000$ and $10 \%$ of FNPV assuming no action on the unfunded liabilities, the archetype is indifferent. ${ }^{49}$ Table 13 reveals how such inertia can impact the outcome of such referendums. In this case, because some voters, especially among 55 year olds, are almost indifferent between the options, they choose not to participate, reversing the outcome so that price indexing wins the referendum.

Table 13-: Hypothetical Referendum Comparing Price Indexing of Bend Points in 2019 to a Benefit Cut in 2035 that does not Affect Those Who Have Retired, with and without Endogenous Voting/Inertia.

\begin{tabular}{|c|c|c|c|c|c|c|c|c|}
\hline & $\begin{array}{c}\text { Share } \\
\text { Voting }\end{array}$ & 1P2 & Indiff & $2 \mathrm{P} 1$ & $\begin{array}{c}\text { Share } \\
\text { Voting }\end{array}$ & $1 \mathrm{P} 2$ & Indiff & $2 \mathrm{P} 1$ \\
\hline & \multicolumn{4}{|c|}{ No Threshold } & \multicolumn{4}{|c|}{ Threshold } \\
\hline Overall & $36.1 \%$ & $28.9 \%$ & $35.2 \%$ & $35.9 \%$ & $36.1 \%$ & $28.9 \%$ & $59.6 \%$ & $11.5 \%$ \\
\hline & By Age & Cohort & & & & & & \\
\hline 25 & $4.5 \%$ & $100.0 \%$ & $0.0 \%$ & $0.0 \%$ & $4.5 \%$ & $100.0 \%$ & $0.0 \%$ & $0.0 \%$ \\
\hline 35 & $5.4 \%$ & $100.0 \%$ & $0.0 \%$ & $0.0 \%$ & $5.2 \%$ & $100.0 \%$ & $0.0 \%$ & $0.0 \%$ \\
\hline 45 & $5.8 \%$ & $0.0 \%$ & $0.0 \%$ & $100.0 \%$ & $5.8 \%$ & $0.0 \%$ & $0.0 \%$ & $100.0 \%$ \\
\hline 55 & $7.2 \%$ & $0.0 \%$ & $0.0 \%$ & $100.0 \%$ & $7.3 \%$ & $0.0 \%$ & $33.7 \%$ & $66.3 \%$ \\
\hline 65 & $6.7 \%$ & $0.0 \%$ & $100.0 \%$ & $0.0 \%$ & $6.6 \%$ & $0.0 \%$ & $100.0 \%$ & $0.0 \%$ \\
\hline 75 & $6.0 \%$ & $0.0 \%$ & $100.0 \%$ & $0.0 \%$ & $5.8 \%$ & $0.0 \%$ & $100.0 \%$ & $0.0 \%$ \\
\hline
\end{tabular}

note: Age Categories are 10 year intervals centered on the age indicated. 18 and 19 year olds are included although not shown. Threshold is the maximum of $10 \%$ of NPV assuming no action on unfunded liabilities and $\$ 10,000$. Voters are indifferent if their change in FNPV in absolute value is less than this threshold.

\section{The Cost of Delay and Missed Opportunities}

The importance of endogenous participation becomes even more apparent when considering the lost historical opportunity to reform Social Security. The long term financial problems of the program have been well understood for three decades (Boskin (1986)). Although presidents Bill Clinton and George W. Bush initiated reform debates in 1997 and 2005, respectively, each floundered. In the former case, a personal scandal, and in the later, the addition of a controversial

\footnotetext{
${ }^{49}$ It is interesting to look at other thresholds, and we explore a different one in the following section.
} 
private account proposal to dealing with the unfunded liabilities, derailed reform. A natural question is, in the absence of these other factors, could reforms have passed back then? To explore this possibility, we engage in a bit of retrospective prospective history, performing an exercise examining hypothetical referendums from the perspective of the year 2000. The SSA's estimate of the actuarial deficit is $50 \%$ larger today than it was in 2000 , and the size of reforms necessary to ensure financial stability have increased proportionally. We ask if, given what people knew then, could an immediate reform have won a referendum, if one was held?

Besides the changes in the program's finances, there have been demographic shifts that have also impacted the probability of reform. As shown previously, if a hypothetical referendum was held today comparing a tax increase in 2019 to a benefit cut in 2035 excluding those near retirement when the trust fund is exhausted, the benefit cut in 2035 wins given the historical voting patterns of the population. Table 14 compares this hypothetical referendum to a similar one held in the year 2000, with the American population and voting proclivities at that time. There are several prominent differences. First the size of the elderly population has increased significantly over the last 18 years, which tends to make immediate reform less likely to win today compared to 2000, because the elderly tend to prefer delayed reforms. This is partially offset by the fact that, relative to 2000 , younger voters are now slightly more likely to vote. The largest difference however, is due to discounting. In 2000, the crisis was much further in the future, so many cohorts had less at stake. The 55 year olds in particular were much closer to indifferent, which could have made them less likely to participate and immediate reform more

likely to prevail. In the previous section when introducing thresholds we used the maximum of $\$ 10,000$ and $10 \%$ of FNPV. Even smaller thresholds however can have big impacts. When we require that archetypes have a difference in FNPV of at least $\$ 5,000$ to participate, although delayed reform wins a referendum in 2019, immediate reform wins if the referendum is held in 2000 as shown in the first and second panels of Table, 14 respectively. In a sense, failure to immediately reform could wind up having delayed reform for 35 years.

In Table 14, the hypothetical referendums being compared are being held approximately 20 years apart. The 25 and 35 year old cohorts in the right hand side of the table are the (surviving) 45 and 55 year old cohorts in the left hand side of the table. In year 2000, the 25 and 35 year olds prefer an immediate tax increase to a benefit cut in 2035, but 18 years later these same individuals prefer a benefit cut in 2035, and since the forcing date is now much closer, fewer of the 45 and 55 year olds are indifferent. The incentives have changed since 2000, along with the demographics and voting patterns, making it more difficult for an immediate reform to win now.

\section{Sensitivity Analysis}

As we have noted throughout this paper, our results depend on a number of assumptions, and at times we had to choose among several plausible options. Our method when such situations arose was to perform sensitivity analyses, typically by changing one assumption at a time, noting which referendums, if any, the assumptions tend to affect. Where any of the assumptions have produced sizable changes, we have examined how the assumptions might interact by varying other assumptions simultaneously. For the sake of brevity, we provide one important informative example, with more detailed explanations and analyses in the Appendix.

The different sets of macroeconomic and demographic assumptions used by the CBO and SSA 
Table 14-: Comparison of Hypothetical Referendums in 2000 versus 2019: Voters Are Indifferent if their Change in FNPV is Less Than $\$ 5,000$.

\begin{tabular}{|c|c|c|c|c|c|c|c|c|}
\hline & $\begin{array}{r}\text { Share } \\
\text { Voting }\end{array}$ & $1 \mathrm{P} 2$ & Indiff & $2 \mathrm{P} 1$ & $\begin{array}{l}\text { Share } \\
\text { Voting }\end{array}$ & $1 \mathrm{P} 2$ & Indiff & $2 \mathrm{P} 1$ \\
\hline & \multicolumn{4}{|c|}{ Tax19 vs Ben35N } & \multicolumn{4}{|c|}{ Tax00 vs Ben35N } \\
\hline & $36.1 \%$ & $28.4 \%$ & $35.7 \%$ & $35.9 \%$ & $39.8 \%$ & $33.2 \%$ & $39.2 \%$ & $27.6 \%$ \\
\hline \multicolumn{9}{|c|}{ By Age Cohorts } \\
\hline 25 & $4.5 \%$ & $95.9 \%$ & $4.1 \%$ & $0.0 \%$ & $4.9 \%$ & $100.0 \%$ & $0.0 \%$ & $0.0 \%$ \\
\hline 35 & $5.4 \%$ & $100.0 \%$ & $0.0 \%$ & $0.0 \%$ & $7.6 \%$ & $100.0 \%$ & $0.0 \%$ & $0.0 \%$ \\
\hline 45 & $5.8 \%$ & $0.0 \%$ & $0.0 \%$ & $100.0 \%$ & $9.0 \%$ & $0.0 \%$ & $4.9 \%$ & $95.1 \%$ \\
\hline 55 & $7.2 \%$ & $0.0 \%$ & $0.0 \%$ & $100.0 \%$ & $7.0 \%$ & $0.0 \%$ & $65.9 \%$ & $34.1 \%$ \\
\hline 65 & $6.7 \%$ & $0.0 \%$ & $100.0 \%$ & $0.0 \%$ & $5.0 \%$ & $0.0 \%$ & $100.0 \%$ & $0.0 \%$ \\
\hline 75 & $6.0 \%$ & $0.0 \%$ & $100.0 \%$ & $0.0 \%$ & $5.5 \%$ & $0.0 \%$ & $100.0 \%$ & $0.0 \%$ \\
\hline
\end{tabular}

note: Age Categories are 10 year intervals centered on the age indicated. Read "1P2" as option 1 , the reform listed first, is preferred to option 2 , the reform listed second.

cause the outcome of two referendums to differ. The CBO predicts a larger deficit, so we increase the size of the benefit cuts and tax increases to close the larger 75 year actuarial deficit, and replace the date of implementation for the delayed reforms with the new exhaustion date (2031). A key driver of the CBO's larger actuarial deficit is the decrease in the share of covered wages below the taxable maximum. We model this increase in inequality by changing the rate at which real wages grow for the lowest income cohort to $1 \%$ and highest income cohort to $1.4 \%$, maintaining an overall rate of real wage growth equal to the CBO's assumed $1.3 \%$.

Table 15 shows the delayed benefit cut excluding those near retirement versus a delayed tax increase in detail, because it is an especially important example. The most preferred delayed reform changes. Under the SSA's assumptions, the tax increase wins, but under the CBO's assumptions, the benefit cut wins. The largest swing is among the 55 year old voters. Under the SSA assumptions, neither reform will affect them, as they are too close to retirement. Under the CBO's assumptions, the forcing event comes in 2031, at which point some of the 55 year old cohort expects it may still be working and thus will have to pay higher taxes on their last years of earnings. The 15 and 25 year old cohorts also experience large swings toward preferring delayed benefit cuts, but since they are less likely to vote than the 55 year olds, the change in their preferences has a relatively smaller impact on the outcome of the referendum.

\section{Coalition Formation}

The voting in many of the referendums in sections 5 and 6 is close. A relatively small percentage of voters swayed to the other side could reverse the outcome. We consider now a hypothetical side payment scheme that could be added on top of an archetypal reform to form a coalition of voters that change the outcome. We use the term coalitions more loosely than in leading game 
Table 15-: Hypothetical Referendum Comparing a Delayed Tax Increase to a Delayed Benefit Cut that Does Not Affect Retired, or Near Retirement, Archetypes

\begin{tabular}{|c|c|c|c|c|c|c|c|c|}
\hline & \multicolumn{4}{|c|}{ SSA Intermediate Assumptions } & \multicolumn{4}{|c|}{ CBO Assumptions } \\
\hline & Share & 1P2 & Indiff & $2 \mathrm{P} 1$ & Share & $1 \mathrm{P} 2$ & Indiff & $2 \mathrm{P} 1$ \\
\hline & Voting & & & & Voting & & & \\
\hline & $36.1 \%$ & $28.5 \%$ & $55.0 \%$ & $16.5 \%$ & $36.1 \%$ & $27.6 \%$ & $35.2 \%$ & $37.3 \%$ \\
\hline & By Age & Cohorts & & & & & & \\
\hline 15 & $0.6 \%$ & $73.1 \%$ & $0.0 \%$ & $26.9 \%$ & $0.6 \%$ & $48.5 \%$ & $0.0 \%$ & $51.5 \%$ \\
\hline 25 & $4.5 \%$ & $100.0 \%$ & $0.0 \%$ & $0.0 \%$ & $4.5 \%$ & $95.9 \%$ & $0.0 \%$ & $4.1 \%$ \\
\hline 35 & $5.4 \%$ & $100.0 \%$ & $0.0 \%$ & $0.0 \%$ & $5.4 \%$ & $100.0 \%$ & $0.0 \%$ & $0.0 \%$ \\
\hline 45 & $5.8 \%$ & $0.0 \%$ & $0.0 \%$ & $100.0 \%$ & $5.8 \%$ & $0.0 \%$ & $0.0 \%$ & $100.0 \%$ \\
\hline 55 & $7.2 \%$ & $0.0 \%$ & $100.0 \%$ & $0.0 \%$ & $7.2 \%$ & $0.0 \%$ & $0.0 \%$ & $100.0 \%$ \\
\hline 65 & $6.7 \%$ & $0.0 \%$ & $100.0 \%$ & $0.0 \%$ & $6.7 \%$ & $0.0 \%$ & $100.0 \%$ & $0.0 \%$ \\
\hline 75 & $6.0 \%$ & $0.0 \%$ & $100.0 \%$ & $0.0 \%$ & $6.0 \%$ & $0.0 \%$ & $100.0 \%$ & $0.0 \%$ \\
\hline
\end{tabular}

note: Age Categories are 10 year intervals centered on the age indicated. Read "1P2" as option 1 is preferred to option 2 .

theoretic political power models. ${ }^{50}$ In any event, consideration of coalition formation to pass, and block, reforms enriches the analysis in some sense, as it is likely that in the political process leading up to the vote, such side payments, in the form of targeted changes to the reforms, would emerge. ${ }^{51}$

Consider the case of a referendum comparing an immediate benefit cut to a delayed cut that does not apply to retired archetypes. With the SSA's assumptions and under American voting proclivities, a benefit cut in 2019 loses the hypothetical referendum (8). In this case, 35 year old and younger cohorts support the benefit cut in 2019 and 45 and older cohorts support the benefit cut in 2035. In the spirit of Dixit and Londregan (1996), we design a side payment scheme to create a coalition with the goal of changing the referendum's outcome so that the reform in 2019 wins. The coalition consists of the young voters plus anyone they are able to convince to support the benefit cut in 2019 with side payments. For example, if people in the 35 year old cohort are $\$ 20,000$ better off in FNPV if a benefit cut in 2019 wins, we expect them to be willing to give up at most $\$ 20,000$ in FNPV to convince other people to support the benefit cut in 2019 . Similarly, suppose people in the 55 year old cohort are $\$ 10,000$ worse off if a benefit cut in 2019 wins. We expect that they are only willing to support the benefit cut in 2019 if they receive a side payment of at least $\$ 10,000$.

We assume that the cost of coalition formation is small relative to the stakes, and that for our purposes we can ignore some strategic behavior and intra-coalition decision making. We

\footnotetext{
${ }^{50}$ For example, Myerson (1991), Acemoglu, Egorov and Sonin (2012) or Scheuer and Wolitzky (2016). We do not claim any elegant theoretical properties of winning coalitions. Nor do we claim the reform is long sustainable in such a game. We do share a belief that framing these issues in game theoretic terms is insightful, and we hope the practical empirical analysis below is illuminating.

${ }^{51}$ An important recent example is the numerous side deals cut to enact the Affordable Care Act in 2010.
} 
can examine which coalitions have the largest, "pot of surplus FNPV," with which to offer compensating side payments to secure a winning coalition or block the formation of a different coalition. To be sure, there are explicit and implicit issues and costs of coalition formation in bundled voting by representatives we ignore. But in the case of Social Security reform, any initial fixed cost is perhaps likely to be offset by the present value of many years of losses or gains from the reforms. Fixed organizational or informational costs could deter coalition formation, but as implied in our results, the coalitions are likely fairly stable from year to year, although the age structure of taxes and benefits suggests that over a longer period they will change.

In this case, young voters identify the older voters who are the least expensive to convince and make a side payment consisting of some of their expected FNPV to the older voters until enough have been convinced to sway the election. We assume the FNPV that funds the side payment comes from the archetypes that gain the most in FNPV from their preferred reform winning, although intra-coalition decision could draw FNPV from the coalition by other means. Every individual within a specific archetype also receives the same dollar side payment in FNPV. The side payments could be accomplished by reducing the size of the cut for targeted older cohorts while increasing the size of the benefit cut for targeted younger cohorts. ${ }^{52}$ Figure 3 shows the outcome of this side payment scheme for our example. The black columns show the difference in expected FNPV of a benefit cut in 2019 and a benefit cut in 2035, summed within age cohorts. The difference is multiplied by the archetype's population share, so the bars show the aggregate difference in expected FNPV for archetypes in the specified age cohort (more accurately, the aggregate expected FNPV with the population normalized to one). The gray columns show the difference in aggregate expected FNPV if a targeted side payment program is tacked onto the benefit cut in $2019 .{ }^{53}$ So the first black column shows that the 25 year old archetypes, in aggregate with the population normalized to one, are a little more than 15,000 dollars in FNPV better off if a benefit cut in 2019 wins compared to a benefit cut in 2035 .

Since the oldest cohorts have significantly lower FNPV if benefit cuts are implemented in 2019 instead of 2035, these cohorts have a negative difference between the two reforms. Married high income cohorts among the 25,35 year olds have to agree to a slightly bigger benefit cut to finance a side payment to the 75 year olds and low income 55 and 65 year olds that makes them exactly indifferent between the two reforms. The bigger benefit cut for the high income 25 and 35 year olds results in lower aggregate FNPV. Subsequently, the gray bars are slightly smaller than the black bars for these ages. Similarly, since the 75 year olds and some 55 and 65 year olds no longer have a negative difference in FNPV between the reforms thanks to the side payments, the aggregate difference in FNPV for the 55 year olds has become less negative. This is represented by a gray bar that is closer to zero than the black bar. In this sense, tailoring the side payments to narrow groups differentially, as in the classic paper by Dixit and Londregan (1996), contrasts with other classic models of the political economy of redistribution, such as Meltzer and Richard (1981), where all individuals face the same transfers. A current benefit cut does not need to exclude all retirees to gain a voting majority over a delayed benefit cut that does exclude all

\footnotetext{
${ }^{52}$ We design the side payment scheme by taking FNPV from the archetype with the largest difference in FNPV between the two reforms until that archetype has a difference equal to the archetype with the second largest difference in FNPV between the two reforms. We then give that FNPV to the archetypes the coalition wants to convince. We continue making side payments until the outcome of the referendum switches, or those attempting to build a coalition run out of FNPV.

${ }^{53}$ See for example Battaglini (2019).
} 
retirees.

Figure 3. : Coalition Formation: Aggregate Difference in FNPV Between a Benefit Cut in 2019 and a Benefit Cut in 2035 by Age Cohort, with and without a Hypothetical Side Payment Scheme.

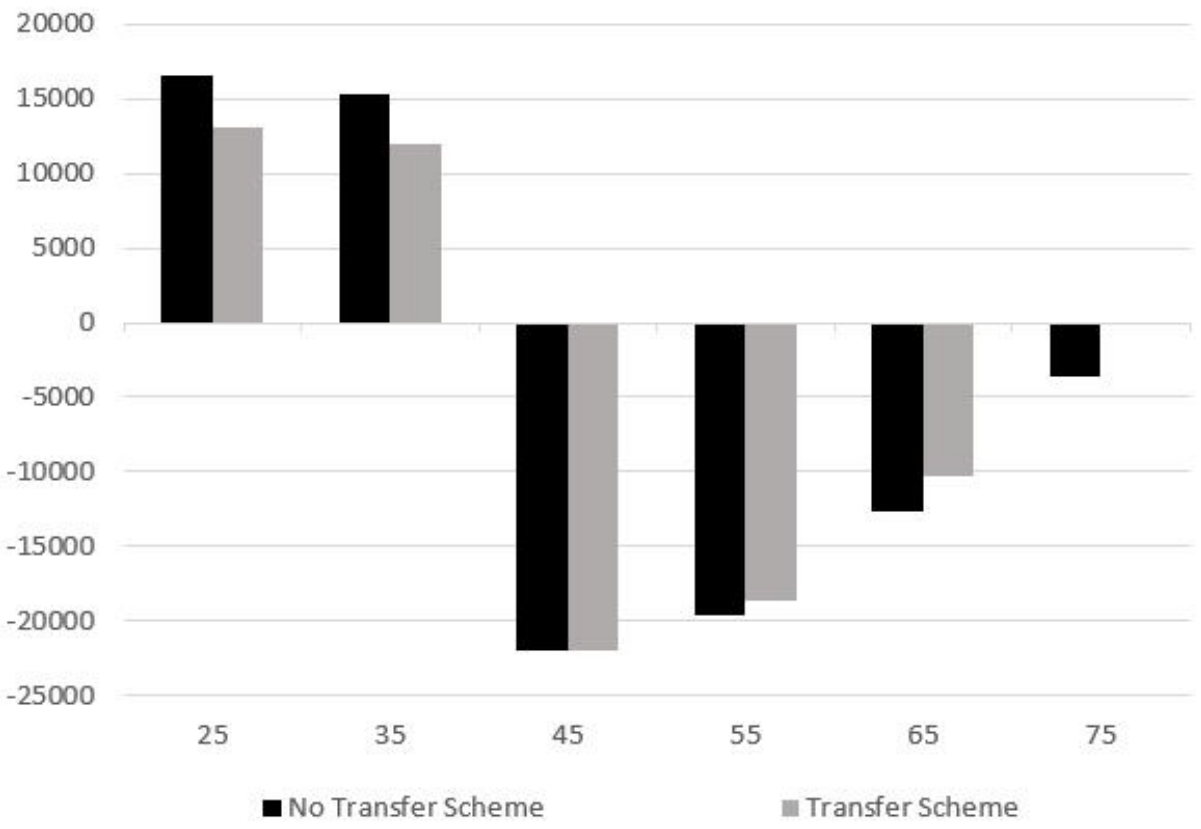

However, in aggregate the difference in FNPV for people preferring a benefit cut in 2035 is larger than the difference in FNPV for people preferring a benefit cut in 2019. A competing coalition could be formed, and because of the larger stakes for those who prefer a later benefit cut, it could outbid the coalition supporting a benefit cut in 2019. This is a common theme among many of our referendums. Reforms that would be implemented immediately are potentially blocked by a coalition with a larger aggregate amount of expected FNPV at stake, given that those under 18 and not yet born do not vote.

In our previous example, the 65 year olds in particular are much worse off if a benefit cut in 2019 gets enacted instead of a benefit cut in 2035. If the 35 year olds make a side payment of $\$ 2,000$ in FNPV to convince some 55 year old archetypes to support a benefit cut in 2019, some 65 year olds could respond by suggesting an alternative side payment scheme where they give $\$ 2,001$ to the 55 year olds. This process could repeat continuously until an equilibrium of this strategic interaction exhausts all the surplus funds of one of the coalitions or, in other words, the winning coalition has to propose a side payment scheme that outspends what an opposing 
coalition could spend. In many cases, the proponents of immediate reforms have less at stake in the aggregate than those who prefer deferred reforms, given that those under 18 and those not yet born do not vote. Their potential gain goes unused in the bargaining. This leads to many coalitions that could support immediate reform being blocked by opposing coalitions.

There is thus a tendency for reforms with the least cost to current and most cost to future voters to be backed by dominant coalitions, which by definition can offer the best deal to current voters. A pattern consistent with this tendency shows up in the referendums with delayed tax hikes and gradual and future benefit reductions, but they still place considerable costs on current voters. The "pure alternative" would be to borrow until all current voters have retired, combined with a currently voted huge tax hike to occur thereafter. Changes of this magnitude would likely be politically unsustainable in the future as pending tax hikes approached, and are not consistent with the results of our YouGov survey or the history of immense resistance to general fund financing of Social Security, which would be the likely method of enabling such borrowing.

One example where blocking by older voters is not possible, however, is price indexing of bend points in 2019 compared to a benefit cut in 2035 that does not affect those near retirement. In this case, those who prefer action now have more aggregate FNPV at stake than those who prefer reform later. The coalition supporting price indexing has to outspend the hypothetical opposing coalition. Figure 4 shows one potential scheme, where the coalition makes the older cohorts exactly indifferent between price indexing and the benefit cut, and then distributes the remaining "gains" from price indexing being enacted equally to the archetypes that supported price indexing originally. There are many different potential ways of dividing the "gains" from winning the referendum, this is only one example. The totality of the reform and proposed side payment scheme would look something very much like phased in benefit cuts combined with some means testing. The switch to price indexing of bend points functionally reduces the expected benefits of individuals who will claim benefits in the future, and the size of the reduction becomes larger over time. The side payments move FNPV from high income archetypes to low income archetypes which could potentially be achieved with some means testing, which was favored in our YouGov survey.

\section{Conclusion}

We calculated the expected net present value of Social Security taxes, benefits, and transfers as currently legislated and under seven archetypal reforms, each closing the long run actuarial deficit, for 112 worker beneficiary archetypes that differed by age, income, and marital status. Using a range of voting behavior patterns and long term economic and demographic projections, we ran a series of hypothetical referenda to demonstrate which reforms are most likely to gain support. Framing the problem as a choice between alternative reforms dealing with the unfunded liabilities is necessary if any reform is to secure a majority vote, since $90 \%$ of voters have a positive expected FNPV of Social Security. Among the reforms that do well in our hypothetical referenda, specifically gradual benefit reductions, partial means testing, and future tax hikes, the latter two also received the most support in the Hoover Institution Survey on Social Security.

Price indexing is the most preferred immediate reform. In situations where the interests of the young are represented, by parents who consider their children's FNPV when voting or by 
Figure 4. : Coalition Formation: Price Indexing of Bend Points in 2019 and a Benefit Cut in 2035 that does not Apply to the Retired or Those Near Retirement, A Competing Coalition Attempts to Block the Coalition Supporting Price Indexing.

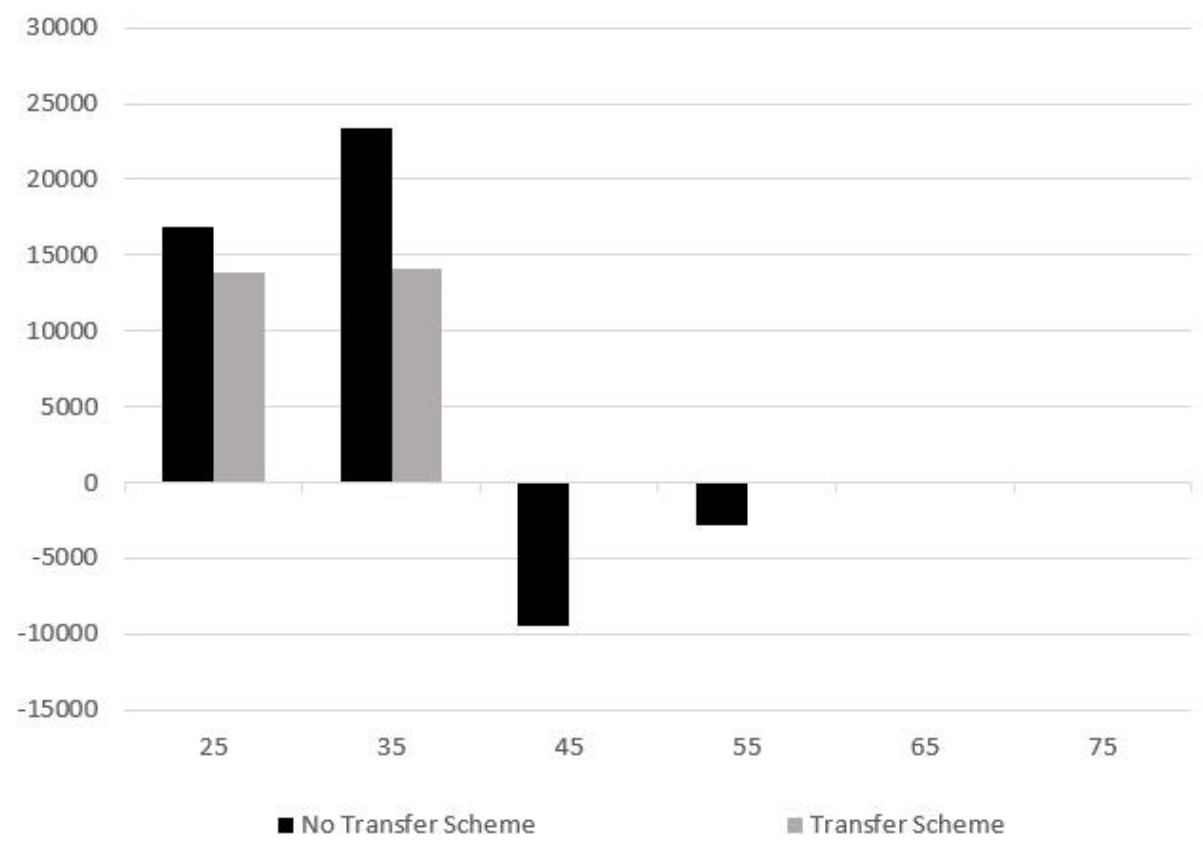

a voting trust, price indexing can win against some delayed reforms. Whether a benefit cut or tax increase is the most preferred delayed reform depends on which assumptions (SSA or CBO) are used to calculate FNPV. Analysis of potential coalitions suggested that, among immediate reforms, price indexing plus some partial means testing for higher income beneficiaries appears to be the only immediate reform capable of withstanding a blocking coalition. Of course, if reform is delayed, in addition to the greater risk of economic disruption to Social Security participants and the overall economy, there might well be turmoil in framing the policy choices on the eve of necessarily precipitous changes in taxes and/or benefits in a few years.

\section{REFERENCES}

Aaron, Henry. 1966. "The Social Insurance Paradox." Canadian Journal of Economics and Political Science, 32.

Acemoglu, Daron, Georgy Egorov, and Konstantin Sonin. 2012. "Dynamics and Stability of Constitutions, Coalitions and CLubs." American Economic Review, 102. 
Auerbach, Alan J., and et al. 2017. "How the Growing Gap in Life Expectancy May Affect the Retirement Benefits and Reforms." The Geneva Papers on Risk and Insurance = Issues and Practice, 42.

Battaglini, Marco. 2019. "Coalition Formation in Legislative Bargaining." NBER Working Paper.

Bee, Adam, and Joshua Mitchell. 2017. "Do Older Americans Have More Income Than We Think?" SESHD Working Paper.

Boadway, Robin W., and David E. Wildasin. 1989. "A Median Voter Model of Social Security." International Economic Review, 30.

Boskin, Michael J. 1986. Too Many Promises: The Uncertain Future of Social Security. Irwin Professional Publishing.

Boskin, Michael J., and John B. Shoven. 1987. "Concepts and Measures of Earning Replacement." In Issues in Pension Economics. University of Chicago Press.

Boskin, Michael J., Laurence J. Kotlikoff, Douglas Puffert, and John B. Shoven. 1987. "Social Security: A Financial Appraisal Across and Within Generations." National Tax Journal, 40.

Brittain, John A. 1971. "The Incidence of Social Security Payroll Taxes." The American Economic Review, 61.

Browning, Edgar K. 1971. "Why the Social Insurance Budget Is Too Large in a Democracy." The American Economic Review, 61.

Clingman, Michael, and Kyle Burkhalter. 2017. "Scaled Factors for Hypothetical Earnings Examples Under the 2017 Trustees Report Assumptions." Social Security Administration Actuarial Note 2017.3.

Congressional Budget Office. 2018. "The 2018 Long Term Budget Outlook."

Deaton, Angus, and Christina Paxson. 1994. "Intertemporal Choice and Inequality." Journal of Political Economy, 102.

Dixit, A., and J. Londregan. 1996. "The Determinants of Success of Special Interests in Redistributive Politics." The Journal of Politics, 58.

et. al., Alicia H. Munnell. 2015. "Report to the Social Security Advisory Board." 2015 Technical Panel on Assumptions and Methods.

Feldstein, Martin S. 1977. "Social Security and Private Savings: International Evidence in an Extended Life-Cycle Model." In The Economics of Public Service. Vol. International Economic Association Conference Volumes. Palgrave Macmillan, London.

for Health Statistics, National Center. 2017. "Health, United States, 2016: With Chartbook on Long-Term Trends in Health." The Centers for Disease Control and Prevention. 
Goda, Gopi S., John B. Shoven, and Sita Slavov. 2015. "Work Incentives in the Social Security Disability Benefit Formula." NBER Working Paper, 21708.

Hammond, P. n.d.. Charity: Altruism Or Cooperative Egoism.

Horsley, Scott. 2016. "The Issues: Hillary Clinton and Donald Trump on Social Security and Medicare." National Public Radio.

Hurd, Michael D. 1989. "Mortality Risk and Bequests." Econometrica, 57.

Luttmer, Erzo F.P., and Andrew A. Samwick. 2018. "The Welfare Cost of Perceived Policy Uncertainty: Evidence from Social Security." American Economic Review, 108.

Mathews, Tj, and Brady E. Hamilton. 2019. "Total Fertility Rates by State and Race and Hispanic Origin: United States, 2017." National Vital Statistics Reports, 68.

Meltzer, Alan H., and Scott F. Richard. 1981. "A Rational Theory of the Size of Government." Journal of Political Economy, 89.

Meyer, Bruce D., and Derek Wu. 2018. "The Poverty Reduction of Social Security and Means-Tested Transfers." NBER Working Paper, 24567.

Moomau, Pamela H., and Rebecca B. Morton. 1992. "Revealed Preferences for Property Taxes: An Empirical Study of Perceived Tax Incidence." The Review of Eoconomics and Statistics, 74 .

Myerson, Roger B. 1991. "Coalitions in Cooperative Games." In Game Theory: Analysis of Conflict. Harvard University Press.

Rangel, Antonio. 2003. "Forward and Backward Intergenerational Goods: Why is Social Security Good for the Environment." American Economic Review, 93.

Saez, Emmanuel, Benjamin Schoefer, and David Seim. 2019. "Payroll Taxes, Firm Behavior and Rent Sharing: Evidence from a Young Workers' Tax Cut in Sweden." American Economic Review.

Samuelson, Paule. 1958. "An Exact Consumption-Loan Model of Interest with or without the Social Contrivance of Money." Journal of Political Economy, 66.

Scheuer, Florian, and Andrew Wolitzky. 2016. "Capital Taxation under Political COnstraints." American Economic Review, 106.

Sjoblom, Kriss. 1985. "Voting for Social Security." Public Choice, 45(3): 225-240.

Steuerle, Eugene C., and Caleb Quakenbush. 2015. "Social Security and Medicare Lifetime Benefits and Taxes 2015 Update." Urban Institute.

Stigler, George J. 1970. "Director's Law of Public Income Redistribution." Journal of Law and Economics, 13.

Tabellini, Guido. 1990. "A positive theory of social security." National Bureau of Economic Research. 